\title{
The CORA dataset: validation and diagnostics of in-situ ocean temperature and salinity measurements
}

\author{
C. Cabanes ${ }^{1, *}$, A. Grouazel ${ }^{1}$, K. von Schuckmann ${ }^{2}$, M. Hamon ${ }^{3}$, V. Turpin ${ }^{4}$, C. Coatanoan ${ }^{4}$, F. Paris ${ }^{4}$, S. Guinehut ${ }^{5}$, \\ C. Boone ${ }^{5}$, N. Ferry ${ }^{6}$, C. de Boyer Montégut ${ }^{3}$, T. Carval ${ }^{4}$, G. Reverdin ${ }^{2}$, S. Pouliquen ${ }^{3}$, and P.-Y. Le Traon ${ }^{3}$ \\ ${ }^{1}$ Division Technique de l'INSU, UPS855, CNRS, Plouzané, France \\ ${ }^{2}$ Laboratoire d'Océanographie et du Climat: Expérimentations et Approches Numériques, CNRS, Paris, France \\ ${ }^{3}$ Laboratoire d'Océanographie Spatiale, IFREMER, Plouzané, France \\ ${ }^{4}$ SISMER, IFREMER, Plouzané, France \\ ${ }^{5}$ CLS-Space Oceanography Division, Ramonville St. Agne, France \\ ${ }^{6}$ MERCATOR OCEAN, Ramonville St. Agne, France \\ *now at: Institut Universitaire Européen de la Mer, UMS3113, CNRS, UBO, IRD, Plouzané, France
}

Correspondence to: C. Cabanes (cecile.cabanes.@ifremer.fr)

Received: 1 March 2012 - Published in Ocean Sci. Discuss.: 21 March 2012

Revised: 9 November 2012 - Accepted: 29 November 2012 - Published: 10 January 2013

\begin{abstract}
The French program Coriolis, as part of the French operational oceanographic system, produces the COriolis dataset for Re-Analysis (CORA) on a yearly basis. This dataset contains in-situ temperature and salinity profiles from different data types. The latest release CORA3 covers the period 1990 to 2010. Several tests have been developed to ensure a homogeneous quality control of the dataset and to meet the requirements of the physical ocean reanalysis activities (assimilation and validation). Improved tests include some simple tests based on comparison with climatology and a model background check based on a global ocean reanalysis. Visual quality control is performed on all suspicious temperature and salinity profiles identified by the tests, and quality flags are modified in the dataset if necessary. In addition, improved diagnostic tools have been developed - including global ocean indicators - which give information on the quality of the CORA3 dataset and its potential applications. CORA3 is available on request through the MyOcean Service Desk (http://www.myocean.eu/).
\end{abstract}

\section{Introduction}

An ideal set of in-situ oceanographic data should cover the entire global ocean and be continuous in time, subject to regular quality control and calibration procedures, and encompass several spatial and temporal scales. This goal is not an easy one to achieve in reality, especially with insitu oceanographic data such as temperature and salinity. These data have as many origins as there are scientific initiatives to collect them. Efforts to produce such ideal global datasets have been made for many years, especially since Levitus (1982).

Among global datasets, the most comprehensive and widely used is the World Ocean Database produced by the National Oceanographic Data Centre (NODC) Ocean Climate Laboratory (OCL). This is a collection of both historical and modern ocean profiles and plankton data. The latest release (World Ocean Database 2009 - WOD09) contains data from the 19 th century to 2009 . Temperature and salinity data are available at observed and standardized levels. More recently, researchers at the Met Office Hadley Centre have produced and maintained a quality-controlled subsurface ocean and salinity dataset (Ingleby and Huddleston, 2007), specially designed for ocean data assimilation systems. The latest version, called EN3, spans the period from 1950 until the present and is updated every month, with temperature and salinity data distributed on observed depths. Sporadically, other groups have also made global hydrographic datasets available, mainly dedicated to research purposes (e.g. Hydrobase, www.whoi.edu/hydrobase/, which provides profile data on observed levels - both raw and quality-controlled; Lozier et al., 1995; Curry, 2001). 
Quality control is a very important step both for reanalysis and research projects, although quality requirements can differ from one user to another. A wide variety of quality control methods exists for in-situ oceanographic datasets, ranging from fully automated methods (e.g. Ingleby and Huddleston, 2007) to the manual checking of every profile. Depending on the dataset, bad data identified by the quality controls are either flagged (e.g. WOD09, EN3) or removed from the database (e.g. Hydrobase, although the raw data files are also provided). WOD09 includes quality control flags for each measurement and profile, although the data on observed levels went through less extensive tests than the standardized ones. Indeed, quality control of the data on observed levels is automatic and aims to detect gross errors or duplicates. Additional checks are applied to the standardized data: density inversions and outliers are flagged (statistics used to find outliers are computed from observed data on each $5^{\circ} \times 5^{\circ}$ square). Moreover, the results from objective mapping of the standardized data are closely examined to detect unrealistic features. Profiles or individual data points that create any unrealistic feature are then visually checked and flagged in both the observed and standard level datasets (see the WOD09 documentation for more details, Johnson et al., 2009). Quality controls applied to the EN3 dataset are based on fully automated methods and include checks against a gridded background and checks against nearby observations (Ingleby and Huddleston, 2007). Data that fail the test are flagged as bad in the dataset. However, with such kinds of fully automatic methods, it can be a challenge to find a compromise between rejecting all the bad observations and retaining all the good ones, particularly in regions with large gradients or small scale eddy variability.

Correction of known instrumental biases should also be a priority in developing global datasets, as the impact of such biases can be serious for climate research studies. Indeed, different issues exist with eXpendable BathyThermograph (XBT) data and, if not corrected, can contribute to anomalous global oceanic heat content (OHC) variability (e.g. Gouretski and Koltermann, 2007; Wijffels et al., 2008; Levitus et al., 2009; Ishii and Kimoto, 2009; Gouretski and Resghetti, 2010; Lyman et al., 2010). In the WOD09 database, the XBT data at observed levels retain the depths received from the data submitter, while the XBT data interpolated to standard levels use the appropriate corrected depth equation when possible and the appropriate time-varying bias correction from Levitus et al. (2009). The EN3 dataset uses the appropriate corrected depth equation for XBTs identified as uncorrected and for some of the XBTs of unknown type (reporting from less than $840 \mathrm{~m}$ and prior to the end of 1996). Moreover, versions of the EN3 dataset include XBT and mechanical bathythermograph (MBT) depth time-varying corrections computed by Ishii and Kimoto (2009), Levitus et al. (2009) and Wijffels et al. (2008). However, these time-varying XBT bias corrections have not been defined for the full time range covered by the EN3 dataset, and XBT corrections have hence been kept constant for the later years. Several widespread problems have also been discovered in the past few years in the Argo data and are known to impact estimates of the global OHC (e.g. Willis et al., 2007; Barker et al., 2011). These data issues have been already corrected by Argo data producers or corrections are still in progress. However, it can be difficult for users to find appropriate information on the state of corrections made on the Argo data included in the global dataset they are working with.

During the decade 2000-2010, the French project Coriolis, whose main aim is to supply in-situ data in real time to French and European operational oceanography programs, started to distribute a quality-controlled dataset named CORA. The first two versions were released in 2007 and 2008. In 2010, as part of the MyOcean project, the Coriolis research and development team developed a new procedure to be able to produce a quality-controlled dataset on a regular basis. Our objective was to update the CORA dataset every year with all the data acquired during the last full year available and to update the entire CORA dataset (full timespan) every $2 \mathrm{yr}$ (the next release of CORA including new data from years 1990-2012 will be made available in the first half of the year 2013). The general purpose was to meet both the requirements of reanalysis projects (GLORYS - Global Ocean Reanalysis and Simulations project, Ferry et al., 2010) including validation, initialization and assimilation of models (Mercator, Lellouche et al., 2012, this issue) and those of general oceanographic research studies, including ones on climate change (e.g. von Schuckmann and Le Traon, 2011; Souza et al., 2011; Guinehut et al., 2012). This new procedure, described in the present paper, was used to produce the CORA3 dataset.

The CORA3 dataset was rechecked with a semi-automated method quite similar to the one presented in Gronell and Wijffels (2008). Statistical tests, performed on the whole CORA3 dataset, helped to identify suspicious profiles. These suspicious profiles were then visually checked, and control quality flags were set to discriminate "bad" from "good" data.

The application of XBT correction to the CORA3 dataset was an application of the method described in Hamon et al. (2012). We also developed simple diagnostics to assess Argo data quality and the status of corrections in our dataset. Estimation of global ocean indicators (GOIs, von Schuckmann and Le Traon, 2011) such as the global OHC or the global steric sea level (GSSL) from in-situ data remains a considerable challenge, as long-term trend estimations of global quantities are very sensitive to any sensor drift or systematic instrumental bias, but can be a useful tool to monitor the quality of such a global in-situ dataset. This type of data validation tool is in particular well suited to detecting large scale errors due to measurement drifts and systematic instrumental biases (e.g. Willis et al., 2008; Barker et al., 2011). In this paper, GOIs are estimated for CORA3 using the method introduced in von Schuckmann and Le Traon (2011), and 
used as a diagnostic of the level of quality reached by the CORA3 database.

In the following sections of this paper, we present the content of the CORA3 dataset (Sect. 2), validation procedures and XBT corrections (Sect. 3), quality diagnostics performed on the CORA3 dataset, including the use of GOIs (Sect. 4), and, finally, the future perspectives for further versions of CORA.

\section{CORA3 dataset content}

The CORA3 dataset contains in-situ temperature and salinity profile data extracted from the Coriolis database, which is updated daily in real time. To better understand the content of CORA3, it is first important to know how data are collected by the Coriolis centre.

\subsection{Data sources}

The Coriolis data centre collects data mainly in real or nearreal time (depending on data sources and availability) in order to meet the needs of operational oceanography. In particular, Coriolis regularly provides real-time quality-controlled and integrated in-situ ocean measurements for the French operational ocean analysis and forecasting system (Mercator Ocean, www.mercator-ocean.fr) to the European GMES (Global Monitoring for Environment and Security) Marine Core Service MyOcean (www.myocean.eu), as well as to several other national systems. Coriolis is a Data Assembly Centre (DAC) for the Argo program (Roemmich et al., 2009, www.argo.ucsd.edu) and, like every DAC, it is responsible for collecting the raw messages from some of the Argo floats, decoding them, quality-controlling them and distributing the data. The Coriolis data centre is also one of the two Global Data Assembly Centres (GDACs) for the Argo program. It collects the Argo data from the other DACs and serves as a distribution point for all Argo data. Every day, the Coriolis data centre collects XBT, CTD and XCTD data from French and some European research ships, as well as from the global telecommunication system (GTS, www.wmo.int), the GOSUD project (Global Ocean Surface Underway Data, www.gosud.org), Voluntary Observing Ships project (VOS, www.vos.noaa. gov/vos_scheme.shtml), moorings - in particular TAO (Tropical Atmosphere Ocean)/TRITON and PIRATA data from PMEL (Pacific Marine Environmental Laboratory) - gliders (www.ego-network.org), and from sea mammals equipped with CTD by French (Centre d'Études Biologiques de Chizé - CEBC - Chizé Centre for Biological Studies, http:// www.cebc.cnrs.fr) and other European Union data providers (through the British Oceanographic Data Centre - BODC and Sea Mammal Research Unit - SMRU). Three times a week, the Coriolis data centre also uploads GTS and GTSPP (Global Temperature and Salinity Profile Programme) files prepared by the Canadian Marine Environmental Data Service (MEDS, www.meds-sdmm.dfo-mpo.gc.ca/isdm-gdsi/ index-eng.html). Delayed mode CTD data are regularly uploaded from the World Ocean Database (WOD09, high resolution CTD data, Boyer et al., 2009).

\subsection{Organisation of the CORA3 dataset}

The CORA3 dataset consists of all the in-situ temperature and salinity profiles extracted at a given time from the Coriolis database, a database which is itself updated daily in real time. For CORA3, which covers the time period 1990 to 2010 , the dates of data retrieval were 25 May 2010 for the 1990-2008 period, 9 September 2010 for 2009, and 22 March 2011 for 2010.

CORA3 contains data from different instrument types: mainly Argo floats, XBT, CTD and XCTD, moorings, sea mammal data, and some drifting buoys.

The data are classified into 7 types, depending mainly on the data source and resolution. Most of these data types are those defined for the GTSPP (PF, CT, XB, BA and TE), while others are "in-house" types (OC and MO). All the data are stored in netcdf files using the same format as that defined for the Argo program, and a naming convention that indicates the data type: PF files are used for Argo data obtained from the DACs; XB files are used for shipboard XBT or XCTD data; CT files are used for shipboard CTD data and CTD data from sea mammals and some sea gliders; OC files are used for CTD and XCTD data from WOD2009; MO files are used for mooring data from TAO/TRITON, RAMA and PIRATA arrays from PMEL; finally, TE and BA files are used for TESAC (TEmperature, SAlinity, Currents) and BATHY (Bathythermograph) data received from the GTS, respectively. However, it can be difficult for users to find all the data from one kind of instrument or probe (e.g. CTD) since it is stored in different types of files (e.g. CT, OC, and TE files for CTD instruments). An effort has therefore been made to identify the "probe type" among the different file types. Eleven "probe types" are defined and a probe type code associated with each profile of the dataset (in an index file). Table 1 gives temperature, salinity and depth/pressure accuracies for each "probe type" as well as the type of the netcdf files where the data are stored.

\subsection{Data coverage}

The CORA3 dataset spans the period 1990-2010. The year 1990 was chosen as a starting point because the Coriolis database does not contain global data before this year. Moreover, reanalysis projects, such as GLORYS, do not go back any further than the early 1990s because they assimilate satellite altimetry. The year 2010 was chosen as the end because it was the last full year available at the time of completing much of the work on CORA3 (i.e. during the year 2011). 
Table 1. Accuracies of the different data types included in CORA3. The type of netcdf files where each data type can be found is also listed (in italic for the most frequent occurrences). Note that data received from the GTS are not full resolution: data are truncated two places after the decimal point for the TESAC (TE) type and one place after the decimal point for the BATHY (BA) type.

\begin{tabular}{|c|c|c|c|c|}
\hline "Probe types" (and the associated codes) & Type of files & $\begin{array}{l}\text { Temperature } \\
\text { accuracy }\end{array}$ & $\begin{array}{l}\text { Salinity } \\
\text { accuracy }\end{array}$ & $\begin{array}{l}\text { Pressure or } \\
\text { depth accuracy }\end{array}$ \\
\hline XBT (10) & $X B, \mathrm{BA}, \mathrm{TE}$ & $0.03-0.01{ }^{\circ} \mathrm{C}^{\mathrm{a}}$ & & $2 \%^{\mathrm{a}}$ \\
\hline CTD (20) & $O C, \mathrm{TE}, \mathrm{BA}, \mathrm{CT}$ & $0.001^{\circ} \mathrm{C}-0.005^{\circ} \mathrm{C}^{\mathrm{a}}$ & $0.02-0.003^{\mathrm{a}}$ & $0.015-0.08 \% \%^{\mathrm{a}}$ \\
\hline XCTD (30) & $B A, T E, \mathrm{OC}, \mathrm{XB}, \mathrm{CT}$ & $0.02^{\circ} \mathrm{C}^{\mathrm{a}}$ & $0.05-0.08^{\mathrm{b}}$ & $2 \%^{\mathrm{a}}$ \\
\hline Argo Floats (40) & $P F$, TE & $0.01^{\circ} \mathrm{C}^{\mathrm{c}}$ & $0.01^{\mathrm{c}}$ & $2.4 \mathrm{db}^{\mathrm{c}}$ \\
\hline TAO/TRITON, PIRATA, RAMA (51) & $T E, \mathrm{MO}, \mathrm{BA}$ & $\begin{array}{l}\text { Standard ATLAS: } 0003-0.03{ }^{\circ} \mathrm{C}(\mathrm{SST}) \\
0.003-0.09^{\circ} \mathrm{C} \text { (subsurface) } \\
\text { Next Gen. ATLAS } 0.003-0.02{ }^{\circ} \mathrm{C}^{\mathrm{d}}\end{array}$ & $0.02^{\mathrm{d}}$ & $1 \mathrm{db}^{\mathrm{d}}$ \\
\hline Gliders (60) & $C T, \mathrm{TE}$ & $0.001{ }^{\circ} \mathrm{C}-0.005^{\circ} \mathrm{C}^{\mathrm{a}}$ & $0.02-0.003^{\mathrm{a}}$ & \\
\hline Sea mammals (70) & $T E, \mathrm{CT}$ & $0.01^{\circ} \mathrm{C}^{\mathrm{e}}$ & $0.02^{\mathrm{e}}$ & \\
\hline Drifting buoys (80) & $T E, \mathrm{BA}$ & $0.002-0.01^{\circ} \mathrm{C}^{\mathrm{a}}$ & $0.003-0.01^{\mathrm{a}}$ & \\
\hline Coastal (52) and other moorings (50) & $T E, \mathrm{BA}$ & Nominal $1^{\circ} \mathrm{C}\left(\text { Achieved } 0.08^{\circ} \mathrm{C}\right)^{\mathrm{f}}$ & $0.001 \mu \mathrm{Scm}^{-1 \mathrm{f}}$ & \\
\hline
\end{tabular}

${ }^{a}$ World Ocean Database, 2009, Boyer et al. (2009); ${ }^{\mathrm{b}}$ Johnson (1995); ${ }^{\mathrm{c}}$ nominal accuracy, Boehme and Send (2005);

${ }^{\mathrm{d}}$ see http://www.pmel.noaa.gov/tao/proj_over/sensors.shtml and references therein; ${ }^{\mathrm{e}}$ Boehme et al. (2009); ${ }^{\mathrm{e}}$ for NDBC buoys, Conlee and Moersdorf (2005).

Figure 1 shows global data coverage for two time periods in the CORA3 dataset: the pre-Argo era in 1990-1999 and the period 2000-2010, during which Argo profiles progressively spread across the global ocean (a near-global scale of coverage was reached in 2005). In the 1990s, high coverage (mostly XBTs) was concentrated on the main shipping lanes. Large gaps are seen in the Southern Ocean, south of $30^{\circ} \mathrm{S}$, even though this region was relatively thoroughly sampled during this period because of the World Ocean Circulation Experiment (WOCE) program in 1990-1998. During the more recent period (2000-2010), the spreading of Argo profiles ensured a minimum coverage of 1-2 profiles per year per $1^{\circ}$ square box (this reached 3-4 profiles per year per $1^{\circ}$ square box after the target of 3000 Argo floats had been met by the end of 2007). Ice-covered or shallow-depth regions are less densely sampled. Regions with more than 10 profiles a year are found in the west side of the North Pacific Ocean, along the US and Canadian east coasts and west coasts of Europe. Some areas in the Southern Ocean are also highly sampled by sea mammals equipped with CTD (first data in 2004).

Figure 2 shows the number of temperature and salinity profiles per month at a given depth in CORA3. Before the year 2000, salinity profiles were essentially from CTDs and often reached down to $3000 \mathrm{~m}$ depth. Since 2000, the number of temperature and salinity profiles reaching down to $2000 \mathrm{~m}$ depth has gradually increased as a result of the growth of the Argo program, but at the same time, the number of deeper CTD profiles has been significantly reduced. Since 20042005, Argo data has been the main source of global subsurface measurements in the CORA3 dataset.

The TAO/TRITON, PIRATA and RAMA array imprint is also clearly visible in Fig. 2 and appears as several distinct well-sampled depths between the surface and $750 \mathrm{~m}$. By the end of 1994, the TAO mooring array had been completed.
This array was equipped with ATLAS (Automated Temperature Line Acquisition System) buoys developed by PMEL's Engineering Development Division that transmitted surface winds, air temperature, relative humidity, sea surface temperature, and ten subsurface temperatures from a $500 \mathrm{~m}$ or $750 \mathrm{~m}$ long thermistor cable. By the end of 2001, the full array was replaced with more modern moorings (Next Generation ATLAS moorings) that allowed the use of additional sensors. In particular, more sites started to transmit subsurface salinity data. The first buoys of the PIRATA array were deployed in the Atlantic Ocean in 1997/1998, while deployment of the RAMA array started in the Indian Ocean in 2000/2001. However, the subsurface salinity data from these moorings were not included in the Coriolis database and CORA3 before 2003, even though some of the buoys measured subsurface salinity before this date.

Figure 3 shows the number of profiles in CORA 3 divided by data type as a function of time. The number of profiles increases after 2001 as the Coriolis data centre was connected to real-time data streams. It can be noted that, in 2000, there is a gap in the acquisition of TAO/TRITON and PIRATA data. This gap and the subsurface salinity gap (before 2003) could have been filled by directly sourcing data from PMEL. However, sourcing data from places other than the Coriolis database compromises our ability to release an update of the CORA dataset every year. Our general approach was first to download data into the Coriolis database and then to update the CORA dataset. These missing data will be added in the next versions of CORA as the complete time series from TAO/TRITON, PIRATA and RAMA buoys become available through OceanSITES.

Since 2004, the importance of coastal moorings has grown (see Fig. 3). These data are mainly from the NDBC (National Data Buoys Centre, http://www.ndbc.noaa.gov/) and are primarily high frequency measurements from moored buoys 


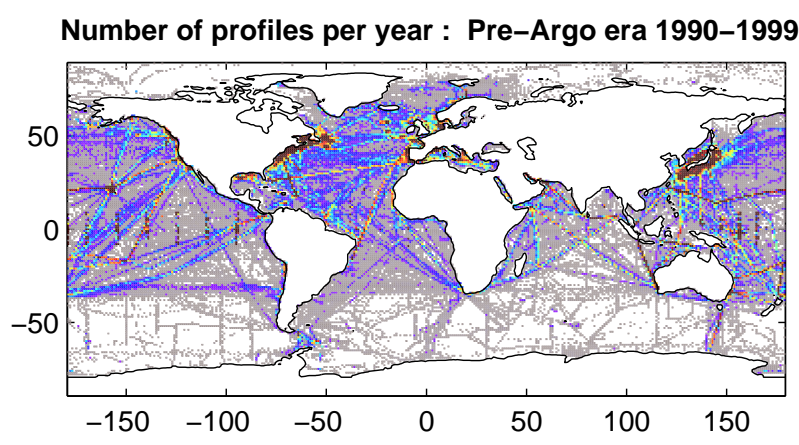

Number of profiles per year : Argo era 2000-2010

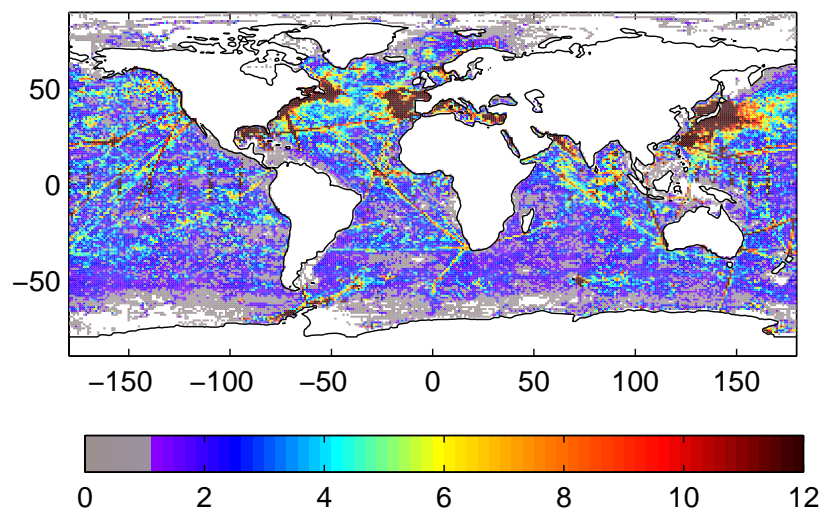

Fig. 1. Number of profiles per year in $1^{\circ} \times 1^{\circ}$ boxes for the period 1990-1999 (upper panel) and 2000-2010 (lower panel) in the CORA3 database.

and shore and platform-based coastal marine stations around the continental United States, Alaska, Hawaii, and the Great Lakes. These data are distributed through the GTS.

\section{CORA3 data processing}

Figure 4 is a diagram of the different stages used for processing the CORA3 dataset. The overall process includes checking for duplicates to ensure that data is unique in the dataset, various quality checks that help differentiate "bad" from "correct" data, and adjustments applied to parameters. These different steps are detailed in the following subsections. Some are processed in real or near-real time and applied to the data freshly downloaded into the Coriolis database; others are processed in delayed time (when the CORA3 files are generated).

\subsection{Checking for duplicate profiles}

Identical profiles can be found with several occurrences in the Coriolis database because different paths can be used to transmit data from sensors to the data centre. Although a duplicate check is performed in real time at the Coriolis data centre, some duplicate profiles slip through. The duplicate check is run when the data are collected, but, because it is
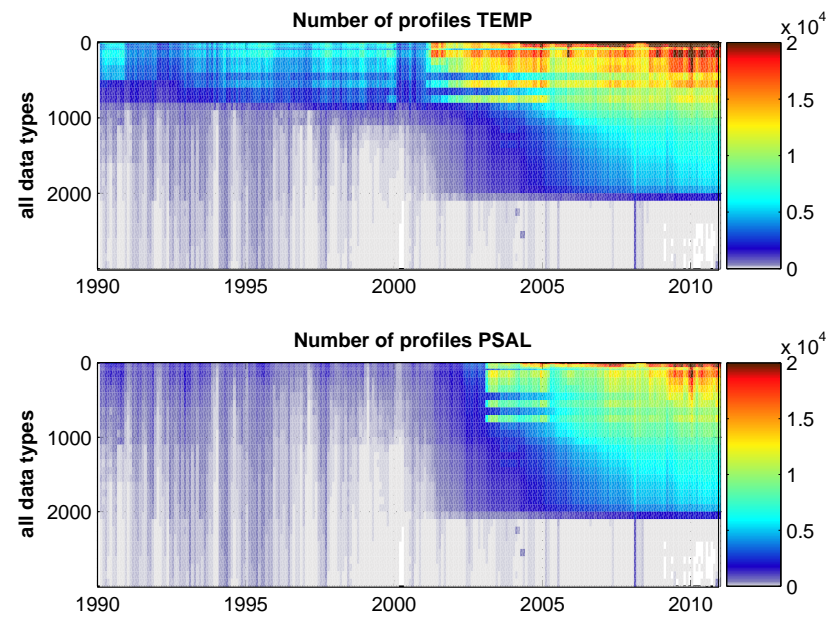

Fig. 2. Number of temperature and salinity profiles in CORA3 per month at different depths and as a function of time.

a real-time process, the duplicate check procedure occasionally fails and then does not run for a short while. Moreover, the duplicate check program run at the Coriolis centre has evolved, but new versions are not systematically run on data already loaded onto the Coriolis database. A new duplicate check was therefore performed on the whole CORA3 dataset.

The duplicate check run in delayed time looks for pairs within $0.1^{\circ}$ longitude and latitude and $1 \mathrm{~h}$ when their types are different (e.g. BA-XB pairs). In this case, the platform identifiers (i.e. float number for Argo floats or ship identifier for XBT or CTD) should be the same. The time window is increased to $24 \mathrm{~h}$ for duplicate screening between PF files (Argo data processed by DACs) and TE files (that may contain Argo data sent to the GTS) because some Argo profiles circulating on the GTS were dated with the Argos localization date instead of the date of the profile (these dates can differ by several hours). When the test is applied for pairs within the same type (e.g. TE-TE pairs), both temporal and spatial criteria are made more precise $\left(0.0001^{\circ}\right.$ and 0.00001 day) and the platform identifiers can be different.

These temporal and spatial criteria serve to identify possible duplicates. Among them, some are exact duplicates, some are duplicates but data or metadata differ slightly because they went through different processing, and others are not duplicates (e.g. an Argo profile and a CTD profile made when the float was launched). Hence, some pairs are systematically excluded from being possible duplicates unless the data are strictly identical (e.g. Argo and CTD or XBT profiles, CTD and XBT profiles, mooring and CTD or XBT profiles). It is also verified that the values of the two profiles selected as duplicates are not too different $\left(0.4{ }^{\circ} \mathrm{C}\right.$ for the mean $T$ and 0.5 PSU for the mean $S$ ). If this is the case, the pair is excluded from the possible duplicate list.

The choice is then made of which record should be kept in the CORA3 dataset. First, there is a preference for records 


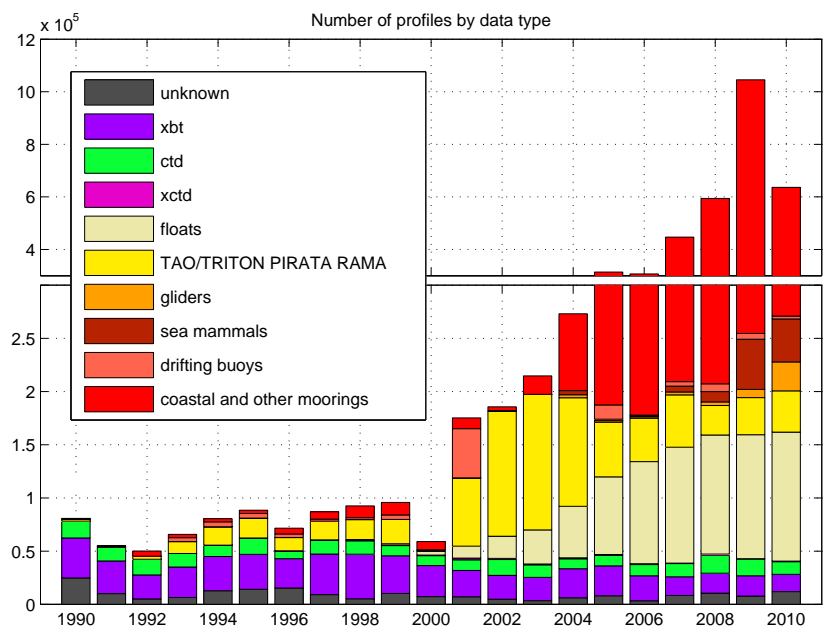

Fig. 3. Number of profiles divided by data type as a function of time.

with both temperature and salinity observations. If this is not decisive, preference is given to the record with the format allowing highest precision (i.e. the GTS formats TE and BA are of lower precision), then to the deepest record with highest vertical resolution. If no choice has yet been possible, the record with less metadata available or the one that appears more often than the other in the list of duplicates is excluded. Finally, if none of those steps is conclusive, an arbitrary decision is made about the deletion of one of the two profiles. In CORA3, $1.5 \%$ of the profiles had at least one duplicate, most of them having only one. We have removed these duplicates from the dataset. A large proportion of the duplicates found were in the BA and TE files (data from the GTS).

\subsection{Data validations}

\subsubsection{Data validations in real and near-real time}

Data validations done in real and near-real time are described in Coatanoan and Petit de la Villéon (2005). Figure 4 shows that most of the data first go through automatic quality checks. These automatic checks are designed for Argo floats (Argo Quality Control Manual, Wong et al., 2012), but are also applied to all other profiles downloaded into the Coriolis database (except for Argo floats managed by other DACs than Coriolis that have been already quality-controlled with the same automatic tests, and sea mammal data that have already been quality-controlled by $\mathrm{CEBC}$ ). Table 3 summarizes the automatic checks applied, for more details see the Argo Quality Control Manual (Wong et al., 2012).

These automatic checks set quality flags for each measurement (i.e. for pressure/depth temperature and salinity at each observed level of a profile), as well as for position and date of the profile. Quality flag values range from 0 to 9 . Their complete definitions are given in Table 2 and are the same as those defined for the Argo program. A flag 1 (good data)

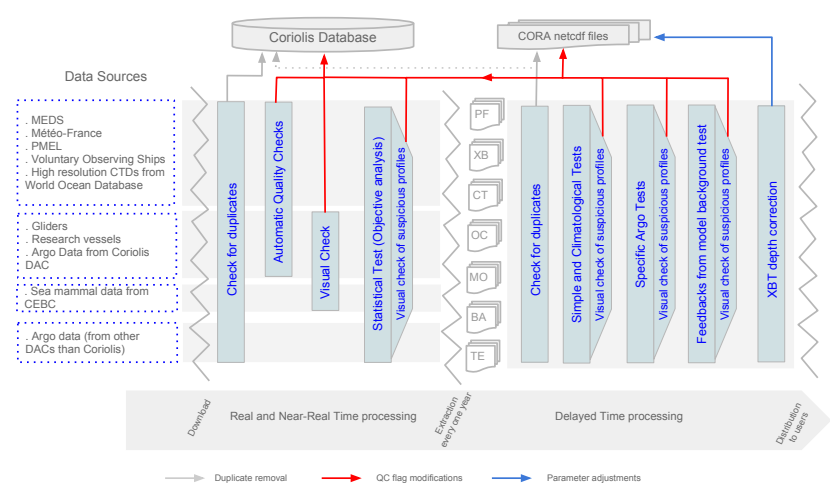

Fig. 4. Data flow diagram showing the various steps of CORA3 data processing.

is attributed to a measurement, position or date unless one of the automatic test fails. A flag 3 or 4 (probably bad or bad data, respectively) is attributed to a measurement, position or date if it fails the automatic test. Position flags are attributed by checking that the latitude and longitude are realistic (Test 3) and correspond to an oceanic position, determined by interpolating a 5-min bathymetry to the profile position (Test 4). Until September 2010, the Coriolis data centre also used a comparison between the bathymetry and the depth reached by the profile to determine whether the position was correct or not. However, in case of steep bathymetric variations, this latter test can erroneously attribute a flag 4 to a position. Some of the erroneous position flags were corrected during the subsequent visual checks (i.e. reset to flag 1). This test is no longer used.

Date flags are attributed during the real-time tests by checking whether the date and time are realistic (Test 2) and whether the platform travel speed between two profiles does not exceed a maximum value defined for each platform type (see Table 3).

Measurement flags are attributed during the real-time tests by checking overall ranges and regional ranges (only for Mediterranean and Red Seas) by detecting spikes and gradients that are too steep. An automatic test is performed to detect and flag density inversions (Test 14). Until October 2011, data downloaded into the Coriolis database were flagged for density inversion if the in-situ density difference between two adjacent levels was negative. As a consequence, density inversions were not well detected by the automatic test. This has been corrected and a new density inversion test is now run as described in Version 2.7 of the Argo Quality Control Manual (Wong et al., 2012). However, the data in the CORA3 dataset have only been checked for density inversions with the older test.

Visual checks are performed by an operator within $48 \mathrm{~h}$ of collection on the data managed by the Coriolis centre (Argo floats from Coriolis DAC, data acquired by French research vessels, gliders), as well as sea mammal data from CEBC. 
Table 2. Quality flags and their definitions.

\begin{tabular}{ll}
\hline Quality code & Meaning \\
\hline 0 & No quality control performed \\
1 & Good data \\
2 & Probably good data \\
3 & Bad data, potentially correctable \\
4 & Bad data \\
5 & Value changed \\
6 & Not used \\
7 & Not used \\
8 & Interpolated value \\
9 & Missing value \\
\hline
\end{tabular}

Temperature and salinity of a profile are displayed and compared to neighbouring profiles and climatology (World Ocean Atlas 2005 - WOA05 Locarnini et al., 2006, and Antonov et al., 2006). This visual approach is combined with an interactive editor, and quality flags for position, date or measurements can be modified if necessary.

A statistical analysis is then performed once a day using all the data available (with quality flags 1 or 2 only), dedicated to detecting possible data problems that could have escaped the automatic tests. The statistical test is based on an objective analysis method (Bretherton et al., 1976) with a three-week window (see Gaillard et al., 2009, for further details). For each profile, a residual is calculated at each standard level and a mean is computed in each layer $(0-100 \mathrm{~m}, 100-300 \mathrm{~m}$, $300-700 \mathrm{~m}, 700-1000 \mathrm{~m}, 1000-1600 \mathrm{~m}, 1600-2000 \mathrm{~m})$. The residual is the difference between the observed value and the analysed field normalized by $\sqrt{\sigma_{\mathrm{UR}}^{2}+\sigma_{\mathrm{ME}}^{2}}$, where $\sigma_{\mathrm{UR}}^{2}$ represents small scales unresolved by the analysis and considered as noise, and $\sigma_{\mathrm{ME}}^{2}$ corresponds to instrumental errors. An alert is produced when the normalized residual computed at a standard level is larger than 8 or when the averaged normalized residual for a layer is larger than 4 .

Profiles with an alert are then visually checked, and control quality flags are examined for all the measurements at each profile level and changed if necessary. The statistical test based on the objective analysis is re-run once a month, as new data may arrive more than 3 weeks after acquisition and are therefore not statistically quality-controlled through the daily analysis. New alerts are produced and visually checked. Control quality flags are changed if necessary. Data that arrive with more than one-month delay will only be qualitycontrolled through automatic procedures before they integrate with the CORA3 dataset.

\subsubsection{Data validation in delayed time}

Once the CORA3 files are extracted from the Coriolis database, the data go through delayed-time validation procedures (see Fig. 4). Only the data considered as good or probably good (flag 1 or 2 ) after real- and near-real-time tests or those which have never been checked (flag 0) are further verified in delayed mode (it should be remembered that the CORA3 dataset contains all the data, even those qualified as bad during the previous real-time tests). Procedures for CORA3 validation include simple tests, comparisons with climatology, and tests designed for Argo floats that verify each suspicious float over its entire lifespan. Finally, a model background check based on the global ocean reanalysis GLORYS2V1 (Ferry et al., 2010) is applied. A test, when it fails, issues an alert on a profile. The profile is then visually checked and control quality flags are examined for all measurements at all profile levels and changed when necessary. Control quality flags are not attributed automatically during this validation phase.

A profile can fail a simple test for several reasons. This can happen when a pressure value is negative (within instrument accuracy), when a temperature or a salinity value is outside an acceptable range according to depth and region (thresholds are those defined in appendix 9 of the World Ocean Database 2005 documentation, Johnson et al., 2006), when temperature or salinity are equal to zero at the bottom or at the surface, when temperature or salinity values are constant at depth, or if there is a large salinity gradient at the surface (more than $5 \mathrm{PSU}$ within $2 \mathrm{~dB}$ ). This latter test has been set up to catch false salinity values near the surface acquired by some CTDs that were not been launched correctly (i.e. data collected without the pump started a few meters below the surface at the beginning the profile).

There are also tests that compare the profile to climatology. The first one determines whether temperature or salinity values are outside the $10 \sigma$ climatological range. The climatology used is the objectively analysed annual fields of World Ocean Atlas 2009 (WOA09, Locarnini et al., 2010; Antonov et al., 2010). Annual climatological fields are used because the seasonal ones are only defined for the top $1500 \mathrm{~m}$. However, the standard deviation takes into account the seasonal variability. The climatology is interpolated to the profile position (bilinear interpolation) and at the observed levels (linear interpolation). The $10 \sigma$ criterion was chosen empirically to reach a compromise between visualizing a lot of good profiles (if the criterion is too strict) and not checking some bad ones (if the criterion is too loose). With this $10 \sigma$ criterion, about $70 \%$ of the alerts had been confirmed after the visual check.

A profile can also fail a climatological test when a systematic offset occurs. The offset is calculated by fitting the difference between the observed and the climatological profile and by minimizing

$\sum_{z=1}^{N} \frac{1}{\sigma_{\text {clim }}^{2}(z)}\left(\left(T(z)-T_{\text {clim }}(z)\right)-\text { offset }\right)^{2}$.

The profile fails this test if the calculated offset is at least 3 times larger than the vertically averaged climatological standard deviation. With this criterion, about $80 \%$ of the alerts 
Table 3. Automatic tests applied (in the order given) to the profiles downloaded into the Coriolis database. Unless stated otherwise, one could refer to the Argo Quality Control Manual V2.7 (Wong et al., 2012) for a complete description of these tests. Some of the automatic tests are only specific to Argo floats (e.g. digit rollover test) and are not applied to the other data types.

\begin{tabular}{|c|c|}
\hline Test name (test number) & Comments \\
\hline Deepest pressure test (19) & Argo only (see Wong et al., 2012). \\
\hline Platform identification (1) & Argo only (see Wong et al., 2012). \\
\hline Impossible date test (2) & $\begin{array}{l}\text { The test requires that the observation date and time from the profile data are } \\
\text { sensible (see Wong et al., 2012). }\end{array}$ \\
\hline Impossible location test (3) & $\begin{array}{l}\text { The test requires that the observation latitude and longitude from the profile } \\
\text { data be sensible (see Wong et al., 2012). }\end{array}$ \\
\hline Position on land test (4) & $\begin{array}{l}\text { Requires that the observation latitude and longitude be located in an ocean. } \\
\text { The bathymetry used is ETOPO5 (Edwards and Arvidson, 1985), which is } \\
\text { interpolated to the profile position. }\end{array}$ \\
\hline Impossible speed test (5) & $\begin{array}{l}\text { If applicable, drift speeds can be calculated given the positions and times of } \\
\text { the platform between two profiles. For Argo floats, drift speed is not } \\
\text { expected to exceed } 3 \mathrm{~m} \mathrm{~s}^{-1} \text {. For XBT or CTD the platform is the ship and } \\
\text { drift speed is not expected to exceed } 25 \mathrm{~m} \mathrm{~s}^{-1} \text {. For glider and sea mammal } \\
\text { platforms, the drift speed is not expected to exceed } 10 \mathrm{~m} \mathrm{~s}^{-1} \text {. }\end{array}$ \\
\hline Global range test (6) & $\begin{array}{l}\text { This test applies a gross filter on observed values for pressure, temperature } \\
\text { and salinity. It needs to accommodate all of the expected extremes } \\
\text { encountered in the oceans (see Wong et al., 2012). }\end{array}$ \\
\hline Regional range test (7) & $\begin{array}{l}\text { Specific ranges for observations from the Mediterranean and Red Seas } \\
\text { further restrict what values are considered sensible (see Wong et al., 2012). }\end{array}$ \\
\hline Pressure increasing test (8) & $\begin{array}{l}\text { This test requires that the profile has pressures that increase monotonically } \\
\text { (see Wong et al., 2012). }\end{array}$ \\
\hline Spike test (9) & $\begin{array}{l}\text { Difference between sequential measurements, where one measurement is } \\
\text { quite different than adjacent ones, is a spike in both size and gradient (see } \\
\text { Wong et al., 2012). }\end{array}$ \\
\hline Gradient test (11) & $\begin{array}{l}\text { This test is failed when the difference between vertically adjacent } \\
\text { measurements is too steep (see Wong et al., 2012). }\end{array}$ \\
\hline Digit rollover test (12) & Argo float only (see Wong et al., 2012). \\
\hline Stuck value test (13) & $\begin{array}{l}\text { This test looks for all measurements of temperature or salinity in a profile } \\
\text { being identical (see Wong et al., 2012). }\end{array}$ \\
\hline Density inversion (14) & $\begin{array}{l}\text { Until October 2011, data downloaded into the Coriolis database was flagged } \\
\text { for density inversion if the in-situ density difference between two adjacent } \\
\text { levels was negative. }\end{array}$ \\
\hline Grey list (15) & Argo float only (see Wong et al., 2012). \\
\hline Gross salinity or temperature sensor drift (16) & Argo float only (see Wong et al., 2012). \\
\hline 18 frozen profile $(18)$ & $\begin{array}{l}\text { This test can detect a float that reproduces the same profile over and over } \\
\text { again with very small deviations (see Wong et al., 2012). }\end{array}$ \\
\hline
\end{tabular}

are confirmed after the visual check. The equation is written for the temperature, but it is applied in the same way for the salinity. An example is given in Fig. 5. An offset is visible: the salinity observations are about 0.5 PSU fresher than the climatological estimate (WOA09), but this is inside the $10 \sigma$ envelope in the area where the standard deviation is large. However, without any other check, it is difficult to say whether the salinity offset is a bias, as this profile only reaches down to $500 \mathrm{~m}$ depth. All the salinity profiles from this platform (a glider that did about 10 profiles a day over 15 days) were then visually checked. All the profiles showed the same offset (even at greater depths) compared to the climatology interpolated to the profile positions and some nearby Argo profiles. It was then decided to flag all the salinity measurements of this profile as bad. This profile passed all the tests and was only detected because of the offset test.

Each time a profile fails a test, it is checked visually and control quality flags of each measurement at each level are examined and changed if necessary. The visual check is a very important step in the procedure since it allows the rejection of observations that have passed the other tests and also allows the requalification of rejected observations as good measurements. In Fig. 6, the first example shows an XBT profile that was partially rejected by the acceptable range test, but for which all observations below $350 \mathrm{~m}$ depth should also be rejected following results of the visual check. In contrast, the example in Fig. 7 shows that a few temperature observations at the bottom of the thermocline are slightly outside the 

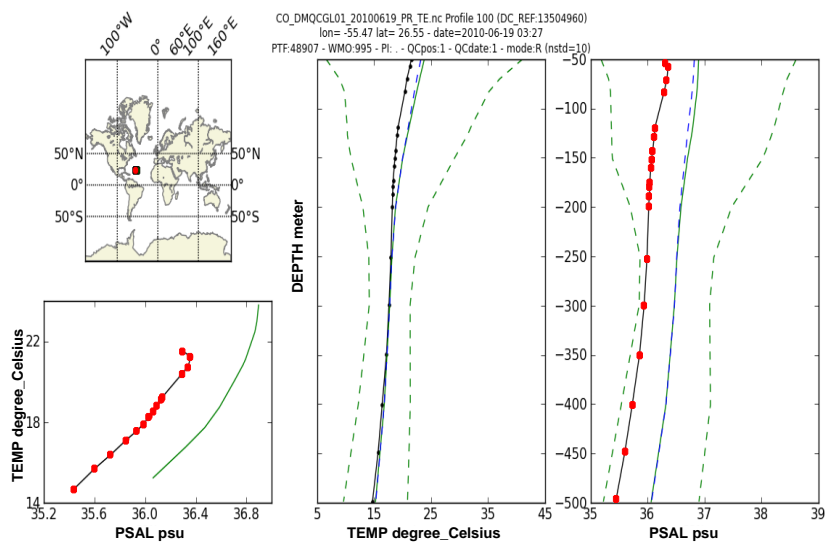

Fig. 5. Example of a profile that fails the offset test for salinity observations. The in-situ profile is shown in black, the climatology and its $10 \sigma$ envelope in green. Red dots indicate observations extracted by the test.

climatology test. During the visual check, these few observations were considered good, which shows that climatological envelope can be used as a first estimation of the quality of an observation but that visual control is a necessary step.

We further test Argo floats whose data have failed the previous simple and climatological tests several times and those suspected to have a problem after comparison with satellite altimetry. A detailed description of the altimetry test is given in Guinehut et al. (2009), of which the results can be found on ftp://ftp.ifremer.fr/ifremer/argo/etc/ argo-ast9-item13-AltimeterComparison/. These floats are verified systematically over their whole life to ensure a homogeneous quality control for all the profiles made by the same float. Profiles of these Argo floats are plotted against the climatology and visualized one by one; each profile is also compared to the previous and following ones. All the profiles from the same float are plotted on a $\Theta-S$ diagram and control quality flags are modified if necessary.

In the framework of the MyOcean global ocean reanalysis work (Ferry et al., 2011), a close collaboration with the French GLORYS reanalysis project enabled a last step in the quality control of the CORA3 dataset to be performed, based on a model background check. The global $1 / 4^{\circ}$ ocean reanalysis GLORYS2V1 (Ferry et al., 2010) is part of the MyOcean "Global Ocean Physics Reanalysis and Reference Simulations" product and assimilated sea surface temperature (SST) and sea level anomaly (SLA). In-situ profiles from a preliminary version of the CORA3 dataset were also assimilated (this preliminary version contained the same profiles as the final version of CORA3 but only covered 1990-2009). The first year of the GLORYS2V1 reanalysis (1993) coincided with the start of the altimetry data from TOPEX/POSEIDON. Once the whole reanalysis was produced, a quality control was made offline that listed suspicious profiles present in the CORA3 dataset. This list was

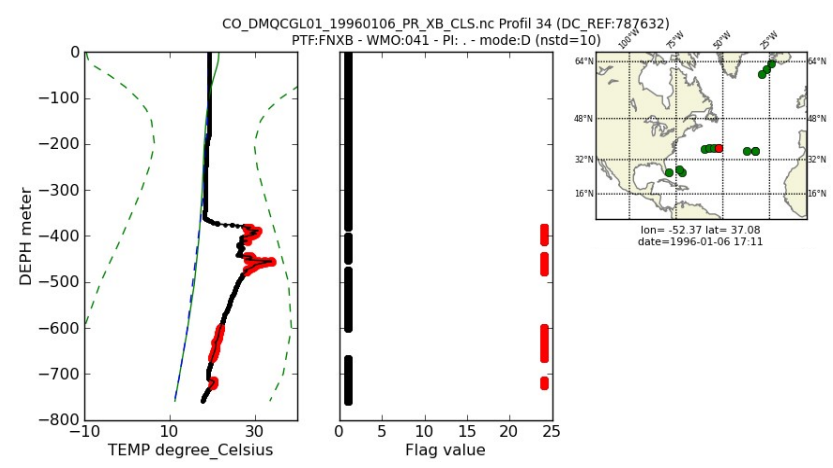

Fig. 6. A temperature profile that is partially invalidated because the temperature values are outside acceptable range (red dots). A visual check is needed to invalidate the other bad values. The quality flags of 24 are only for the purpose of the plot and indicate that this test (acceptable range) fails at some observed levels of the profile. This profile was visually checked before any flag was modified in the CORA3 dataset. After visualization, all the temperature values measured at depths below $360 \mathrm{~m}$ were flagged as bad data (flag 4) in the CORA3 dataset.

transmitted to the Coriolis data centre in order to check its contents and, if necessary, flag observations in the final CORA3 dataset. Below, we describe the method used to detect those suspicious profiles.

Based on this 17-yr-long reanalysis, "innovation" (i.e. observation minus model background) statistics for in-situ temperature and salinity profiles were collected and used to detect suspicious profiles and provide a black list of observations present in CORA3 dataset. This observation screening is known as background quality control. The probability density functions (PDFs) of the innovations are calculated as a function of spatial location $(x, y, z)$ in the global ocean. We find that in most places, innovation PDFs are very close to a normal distribution. Therefore, we assume that innovations have a Gaussian distribution and that the tails of the probability density function contain suspicious observations. First, the collected innovations are binned on a $5^{\circ} \times 5^{\circ}$ grid on the horizontal, the model vertical grid, and the season. In each cell of this 4-dimensional grid, we estimate two parameters, which are the mean $M$ and standard deviation STD. These parameters are used to define the following space- and season-dependent threshold value:

$T=|M|+N \times \mathrm{STD}$,

with $N$ being an empirical parameter.

In a second stage, we perform the observation screening for each profile. At a given depth, an observation is considered suspicious if the following two criteria are satisfied:

$$
\begin{aligned}
& \text { 1. } \mid \text { innovation } \mid>T \\
& \text { 2. } \mid \text { obs-clim } \mid>0.5 \text { |innovation } \mid
\end{aligned}
$$

The first criterion diagnoses whether the innovation is abnormally large, which would most likely be due to an erroneous 

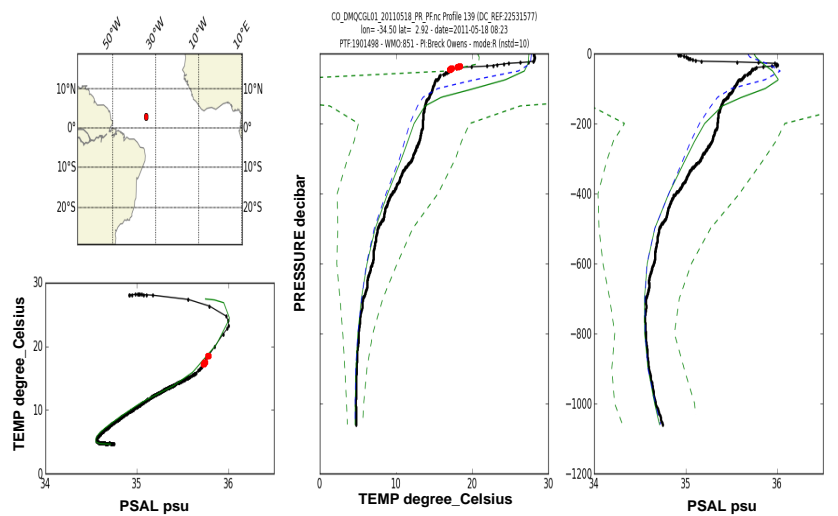

Fig. 7. A profile that fails the climatology test using an envelope at $10 \sigma$ but that was requalified as good after a visual check. Red dots indicate observations extracted by the test.

observation. Condition 2 avoids rejecting "good" observations (i.e. those that are close to the climatology) in the case of a biased model background. In the case of a good observation and a biased model background, LHS of criterion 2 is small and RHS is large, implying that the condition is not satisfied. This criterion significantly reduces the number of good observations that may be rejected (false alarms). The threshold value (0.5) in test 2 is empirical and has been tuned in order to minimize the false alarms. A small threshold value implies fewer false alarms, but also fewer detections of bad profiles.

The results of this background quality control are summarized in Fig. 8, where the percentage of suspicious temperature and salinity profiles is displayed as a function of the year over the period 1993-2009. We expect this percentage of suspicious profiles to be relatively stable during the reanalysis time period. It is almost the case for the temperature profiles, with little year-to-year variability. For salinity, one can see a peak between 1999 and 2001. A more detailed analysis revealed that, following the strong 1997/1998 ENSO (El Niño-Southern Oscillation) event, more suspicious salinity profiles than usual were detected in the tropical Pacific. This happened until 2001 with the strong La Niña. This is attributed to the fact that the threshold values defined for the quality control salinity may be underestimated because the statistics may not contain enough ENSO events to fully sample the ocean variability. In 1998, only $30 \%$ of the suspicious profiles identified with this background quality control were confirmed to have at least one bad measurement. Finally, in the CORA3 dataset, quality flags were only modified for those measurements that were confirmed to be bad after visual check.

Figure 9 shows the spatial distribution of suspicious temperature and salinity profiles in 2009 . The reasons for erroneous measurements are numerous. They can be due to a sensor (pressure, temperature, salinity) defect or ageing, or may result from transmission errors. These reasons are a priori

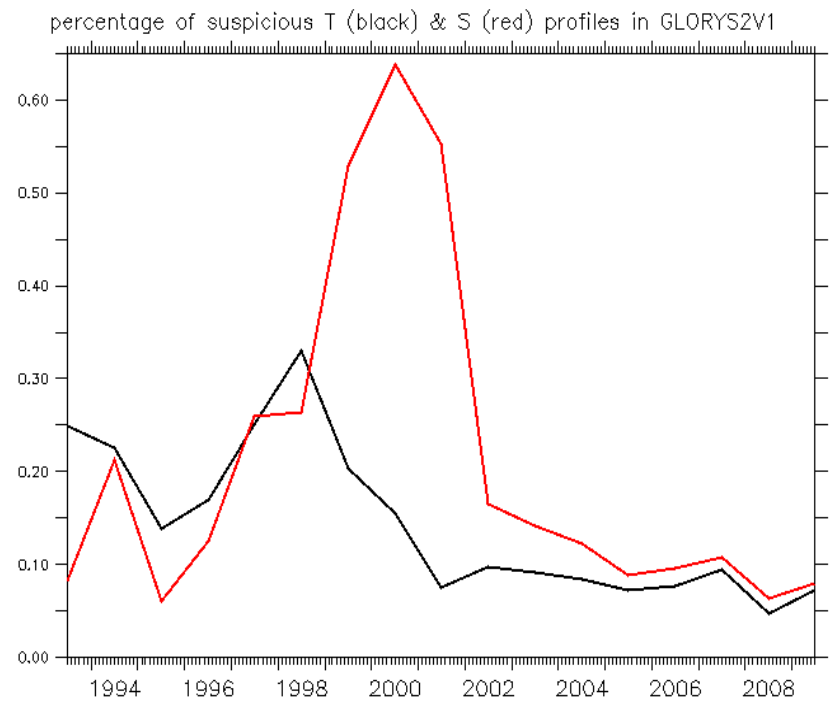

Fig. 8. Percentage of suspicious temperature (black) and salinity profiles (red) as a function of year in GLORYS2V1 reanalysis quality control. The profile grey list was provided to the Coriolis data centre to improve the quality of CORA3. See the text for more details.

independent from the profile location. Therefore, erroneous profiles are expected to be randomly distributed in space, which is almost the case. However, we can see some places where there are concentrations of points (e.g. in the central tropical Pacific or east of the Philippines) corresponding to a moving Argo float with defective sensors. An example of suspicious profiles and their impact on an ocean analysis can be found in Lellouche et al. (2012).

For the years 1993 to 2009, the background quality control allowed identification of 2760 suspicious temperature and salinity profiles, which were reported to Coriolis to improve the CORA3 dataset. All these profiles were then visually checked and about $50 \%$ of them were confirmed to have at least one bad measurement. Their control quality flags were then modified correspondingly. The other $50 \%$ corresponded to false alarms or profiles whose quality was difficult to evaluate. In these cases, the quality control flags were left unchanged.

\subsection{Data corrections}

The CORA3 dataset not only contains the raw parameters such as temperature, salinity, pressure or depth, as received from the instrument, it can also include adjusted parameters, i.e. temperature, salinity, pressure or depth corrected from a drift or offset. The data types affected by these adjustments are Argo floats and XBTs. For Argo data, it is the responsibility of each DAC to provide data corrections both in real time and delayed mode. The Coriolis data centre, as a GDAC, gathers these corrections and stores raw and adjusted parameters in the Coriolis database. No supplementary correction 


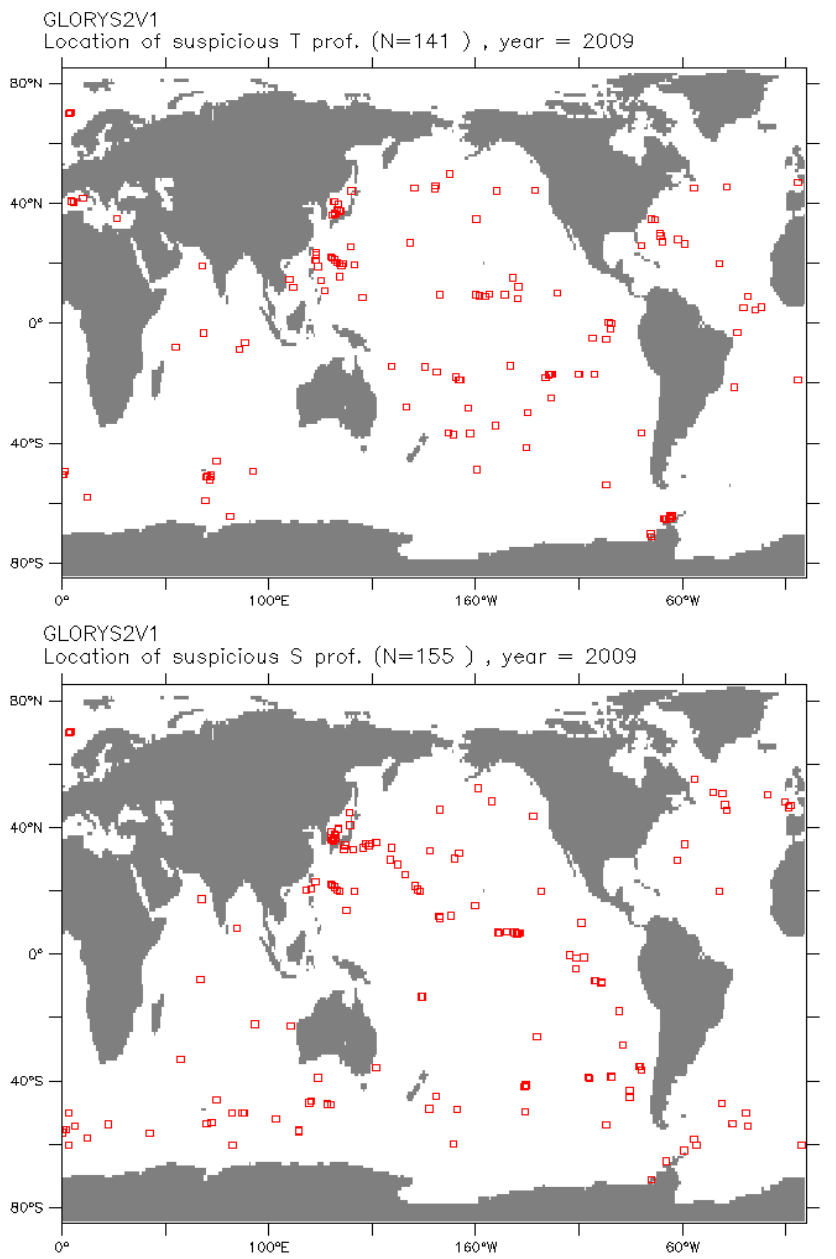

Fig. 9. Geographical location of suspicious temperature (top) and salinity (bottom) profiles diagnosed in 2009 with GLORYS2V1 quality control.

has been made or applied to the Argo data in the CORA3 dataset. On the contrary, corrections for XBT data were calculated as part of CORA3 data processing. The method is described in Sect. 3.3.2.

\subsubsection{Corrections for Argo floats}

For Argo data, the adjusted parameters are salinity and pressure, which may be adjusted in real time in an automated manner or in delayed mode (see the Argo quality control manual, Wong et al., 2012, for more details). Salinity is corrected in delayed mode by the principal investigator (PI) of the float by comparing the observed value to neighbouring historical CTD data (Wong et al., 2003; Boehme and Send, 2005; Owens and Wong, 2009). The requirement for pressure corrections depends on the float model. Most of the Argo array is currently comprised of three float models: the APEX floats produced by Teledyne Webb Research, the SOLO floats manufactured by Scripps Institution of Oceanography, USA and WHOI (Woods Hole Oceanographic Institution), and the PROVOR floats developed by Martec MetOcean and IFREMER (Institut Français de Recherche pour l'Exploitation de la Mer). While PROVOR and SOLO floats are designed to self-correct any pressure drift, APEX floats do not make any internal pressure correction as they return "raw" pressures. For this latter float model, adjustments are applied both in real time (by the DACs) and delayed mode (by the PIs) by using the surface pressure values returned by the float (surface pressure is measured while the float surfaces and it is assumed to be zero if no sensor drift exists). However, delayed mode processing is a long-term task and some floats have not yet been reprocessed. Some simple diagnostics on the state of corrections for Argo data in the CORA3 dataset are given in Sect. 4.1.2.

\subsubsection{XBT bias corrections}

The XBT system measures the time elapsed since the probe entered the water and, thus, any inaccuracies in the fall-rate equation will result in depth errors. A study of Hanawa et al. (1995), based on comparisons with CTDs, proposed a new fall-rate equation for some types of XBTs (T-4, T-6, T-7 and Deep Blue models). In 1995-1996 Sippican and TSK manufacturers implemented this new fall-rate equation. However, other sources of XBT temperature uncertainties and biases exist (Gouretski and Reseghetti, 2010; Gouretski and Koltermann, 2007). For example, it has been known since the use of these probes started that the fall rate should depend on the physical characteristics of seawater like viscosity, temperature, and density (Thadathil et al., 2002; Kizu et al., 2011). It was also suggested early on that the assumption of a terminal velocity might not be always correct, in particular in the surface layer, and, compounded with time constant issues, can result in a depth offset (although the determination of this depth offset is not straightforward, as discussed by di Nezio and Goni, 2011). Moreover, the weight and hydrodynamic characteristics of the probe and/or wire are known to strongly influence the fall-rate equation. Seaver and Kuleshov (1982), for example, indicate that a weight uncertainty of $2 \%$ could induce an $8.8 \mathrm{~m}$ depth error at $750 \mathrm{~m}$. A variety of approaches have been used to correct these biases (e.g. Wijffels et al., 2008; Levitus et al., 2009; Ishii and Kimoto, 2009; Gouretski and Reseghetti, 2010; Hamon et al., 2012). The correction applied on the CORA3 dataset is an application of the statistical method described in Hamon et al. (2012). This correction is based on the comparison of XBT profiles with co-localized reference profiles (CTD). The correction is calculated for each year and divided into two parts: first the computation of a depth-independent temperature correction (temperature offset) based on comparisons with reference profiles in the near surface layer and then a correction of the depth with a second order polynomial function. For further details of this method, the reader should refer to Hamon et al. (2012). Rather than use the coefficients given in Table 2 of Hamon 
et al. (2012), for several reasons, we recompute them. First, the coefficients given in Hamon et al. (2012) only go up to 2007, while we also need them for the last $3 \mathrm{yr}$ of the CORA3 dataset (2008-2010). Second, looking at Fig. 5 in Hamon et al. (2012), it appears that the corrections computed for the 2000s are based on fewer collocated pairs than for the years before. We therefore decided to use not only CTD profiles, as in Hamon et al. (2012), but also data from Argo, drifting and moored buoys (those with quality flags 1 or 2 only) to get more reference profiles co-localized with XBTs. In this way, we obtain between 6000 and 16000 collocated pairs each year between 2002 and 2010, which is much more than if only CTDs had been used as reference profiles. We are also not certain whether the new Hanawa fall-rate equation was applied for a large proportion of the XBTs in CORA3. This is because information on the XBT model and the fall-rate equation applied is missing for many XBT profiles (mainly before 1995 and for XBT data transmitted through GTS). We thus chose not to apply the Hanawa fall rate for XBT depth computed with the old fall-rate equation (Hanawa et al., 1995). This differs from Hamon et al. (2012), where the linear Hanawa correction was first applied when possible. The coefficients computed in our case slightly differ from those given in Hamon et al. (2012), because they are computed with different reference profiles and because they compensate for the fact that we did not apply the Hanawa correction for a part of XBT profiles.

In the CORA3 dataset, we applied the correction based on the Hamon et al. (2012) method for all the XBT profiles in $\mathrm{XB}, \mathrm{BA}$ and TE files with an instrument type that refers to an XBT probe (see www.nodc.noaa.gov/GTSPP/document/ codetbls/gtsppcode.html). Profiles in XB files with an unknown instrument type and no salinity data (to avoid XCTD) were also considered as XBT. But profiles with an unknown instrument type in BA or TE files could not be qualified as XBT since many different instrument types are included in these files.

\section{CORA3 diagnostics}

\subsection{Quality and known data issues}

\subsubsection{Overview}

Figure 10 shows the percentage of profiles in the CORA3 dataset that have bad quality flags (flags 3 or 4 ) for position, date or for at least $75 \%$ of temperature or salinity measurements. To produce these statistics, the best profile available is used, meaning that if temperature or salinity has been corrected in delayed mode (for Argo and XBT data), then the adjusted profile and associated quality flags are taken into account instead of the raw profile.

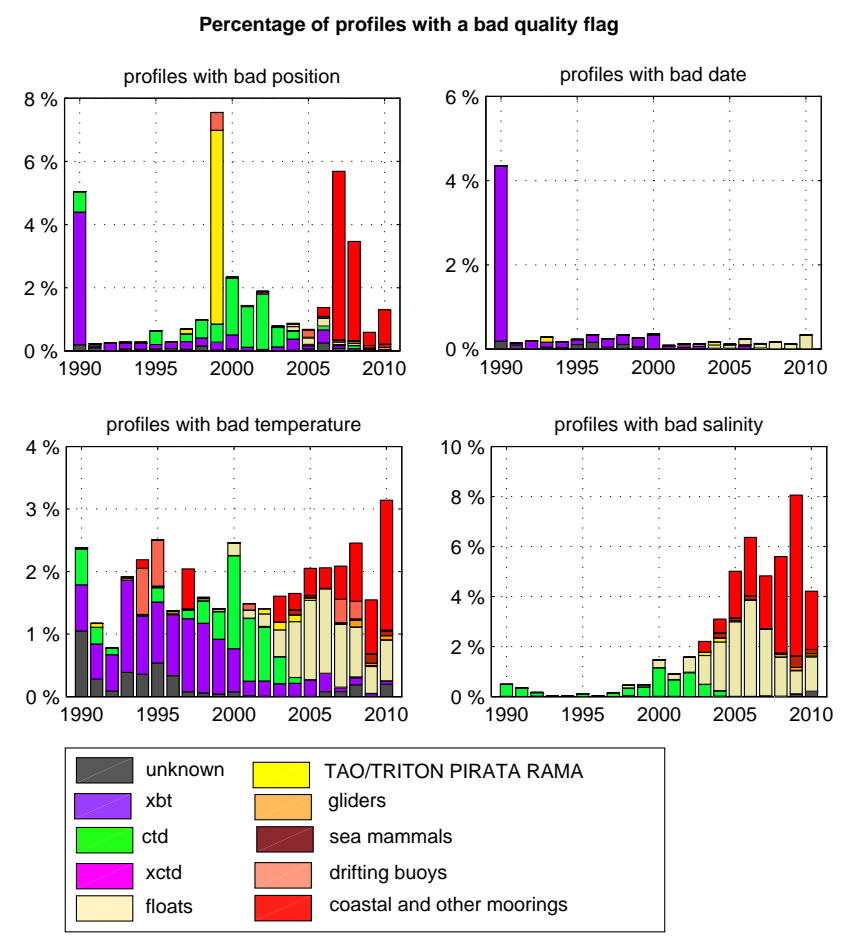

Fig. 10. Percentage of the profiles with bad quality flags in CORA3 as a function of time and data type.

As shown in Fig. 10, the percentage of profiles with a bad position in the CORA3 dataset is highly variable from one year to another. For 1999, the percentage of profiles with a bad position is close to $8 \%$ in the dataset, mainly due to incorrect positions of TAO/TRITON moorings. To date, we have no explanation for this. It should be noted that TAO/TRITON, PIRATA and RAMA data in the CORA3 dataset are those received in real time from PMEL and GTS. These positions are therefore the nominal positions and not the measured ones. The nominal position can differ significantly from the measured one if a buoy was not deployed at exactly the nominal site and/or (but to a lesser extent) because of the movement of the buoy around the anchor point. After 2005, the profiles with a bad position are mainly those from some high frequency coastal moorings, probably because they are located very close to the coast, in port or estuary areas (thus, the position might be real, but detected on land by the test). Except for 1990, the percentage of profiles with a bad date is lower than $1 \%$ in CORA3. The percentage of bad temperature profiles ranges between 1 and $3 \%$ while the percentage of bad salinity profiles is lower than $2 \%$ before 2003 and ranges between 2 and $8 \%$ afterwards. After 2003, a large proportion of salinity profiles were obtained from Argo floats. The percentage of bad salinity profiles among Argo floats is quite high, mainly because of a problem encountered with one float type (see the next subsection for more details). However, the percentage of bad 
salinity profiles among Argo floats started to be lower after 2007 , once the problem was discovered and resolved. In the CORA3 dataset, the percentage of profiles with bad salinity data is still high after 2007 mainly because of data from coastal moorings. The quality of these high frequency moorings is difficult to evaluate with the tools we developed, as many of them are located in areas influenced by tides or estuarine processes and thus salinity measurements are very different from open-ocean climatology. As a consequence, while running our tests, we get thousands of alerts coming from some of these high frequency moorings. As it is not possible to visualize them one by one, we took the decision to flag as bad all the data from coastal high frequency moorings with an alert. We are now working on more appropriate tests for this type of data.

\subsubsection{The special case of Argo floats}

Since the beginning of the Argo program, several data problems have been identified and corrections have been made or are in progress in each DAC. As a consequence, the Argo database is constantly evolving - even for the data acquired some years ago - as some floats can be reprocessed a long time after data acquisition (1-2 yr on average). The most upto-date Argo database is on the GDAC ftp servers. Therefore, it is important to have in mind that, for Argo data, the CORA3 dataset reflects the status of the Argo database on the GDAC ftp servers at the date of data retrievals (mid-2010 for data that span 1990-2009 and March 2011 for the year 2010). These data were rechecked during the validation phase of CORA3 (as described in Sect. 3) to improve the data quality in a homogeneous way, but no supplementary data correction was applied. Some simple diagnostics about Argo data quality and state of corrections in the CORA3 dataset are therefore highly necessary.

For the CORA3 dataset, the adjusted parameters for Argo data are those received at the GDAC at the date of the retrieval. In the CORA3 dataset, about $75 \%$ of Argo float profiles are adjusted for pressure and/or salinity (63\% in delayed mode and $12 \%$ in real time, automatically).

Figure 11 shows the percentage of Argo profiles that have a bad quality flag either for position, date or at least $75 \%$ of temperature or salinity measurements. The different colours indicate the different float models (mainly APEX, SOLO and PROVOR). Most of the floats are fitted with SBE (Seabird Electronics, Inc.) CTD sensors, while a smaller number, deployed mostly by WHOI, are fitted with FSI (Falmouth Scientific Instruments) sensors. Argo profiles with a bad position represent less than $1 \%$ of the total number of Argo profiles. However, during the 2004-2006 period, there were higher numbers of floats with position errors than the other years. Looking at these floats, most of them $(80 \%)$ are handled by the Indian DAC (Indian National Center for Ocean Information Services - INCOIS), and their position flags are set during their real-time controls. Whether or not the

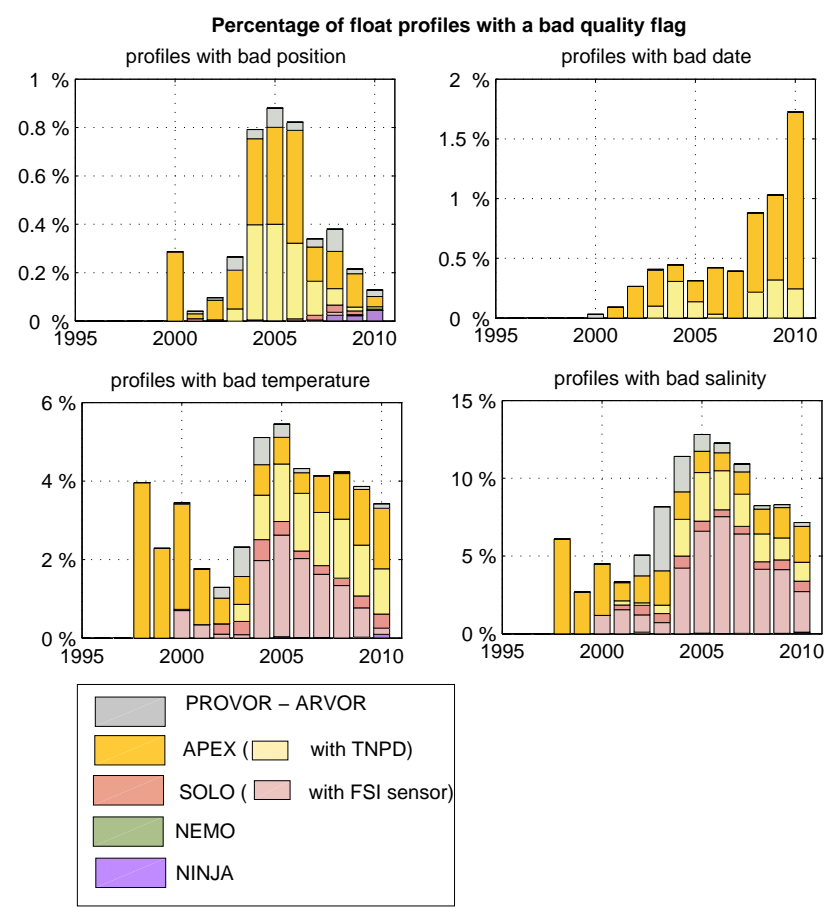

Fig. 11. Percentage of the Argo profiles with bad quality flags as a function of time.

position errors for these floats are justified needs to be investigated further. The percentage of Argo profiles with a bad date increased after 2007, reaching up to $2 \%$. A large proportion of Argo profiles with bad temperatures and bad salinities originate from SOLO floats (mainly WHOI SOLO floats with FSI CTD sensors). At the beginning of the year 2007, a large number of SOLO FSI floats were found to have a pressure offset due to a software error. In the aggregate, the WHOI FSI floats resulted in a cold bias. The problem was identified and, by the end of 2007, corrections were put on the GDACs for some of these floats (39), while the uncorrectable floats (165) were grey-listed (i.e. pressure measurements flagged as bad data). We checked that the grey list was applied to the CORA3 dataset. Finally, about $87 \%$ of the profiles from SOLO floats with FSI sensors are unusable in the CORA3 dataset because the position, the date, the pressures or the temperatures have been flagged as bad.

There have been various other issues with the pressure measurements, reported at different times. By mid-2002, SBE had chosen to install pressure sensors from Druck Corporation in all of their CTDs, mainly because of their stability. However, in early 2009, a problem was found with the Druck pressure sensor. It revealed an increase in the occurrence rate of floats exhibiting negative surface pressures for floats deployed in 2007 and after (3\% prior to 2007 and 25$35 \%$ after 2007, Barker et al., 2009). This problem was especially critical for APEX floats, which do not make any internal pressure correction (contrary to SOLO and PROVOR floats). Moreover, at that time, most of the DACs were not 
correcting the pressure of APEX floats (by using the measured surface pressure), either in real time or in delayed mode. Indeed, most of them only started to apply such a pressure correction during 2009.

However, some APEX floats are uncorrectable, either because essential technical information is missing or because the surface pressure is not known. Indeed, some versions of the software that controls APEX floats (APF 8 and earlier controller board versions) were set to report only positive surface pressures and to truncate negative surface pressures to zero. In this case, if the pressure sensor drifts toward negative values, the reported surface pressure is always zero and thus the float is uncorrectable. Truncated negative pressure drift (TNPD) refers to the part of these float time series from which surface pressure continuously reads zero without reverting back to positive values for at least 6 months. In delayed mode, the float PIs are asked to flag the data (TEMP, PRES and PSAL) of TNPD floats as bad (flag 4) when float data show observable temperature and salinity anomalies that are consistent with increasingly negative pressure drift, and to flag the data of TNPD floats as probably good (flag 2) otherwise (see the Argo quality control manual, Wong et al., 2012, for more details). Following the method described in the Argo quality control manual (Wong et al., 2012), we could identify 100955 profiles with TNPD (about $20 \%$ of all APEX floats profiles) in the CORA3 dataset. We did not perform specific quality checks for these profiles, but a fraction of them has been already flagged as bad thanks to the previous tests: among all the profiles we identified as TNPD, about $13 \%$ are flagged as bad either for pressure, temperature or salinity. However, only severe negative pressure drifts show observable temperature and salinity anomalies (an error of $-20 \mathrm{dbar}$ would cause a positive salinity error of approximately 0.01 PSS-78). Barker et al. (2011) estimated a median error of $-3 \mathrm{dbar}$ for all TNPD profiles that can be compared with a close good profile. As a consequence they recommended that all the TNPD floats be excluded from studies of oceanic heat content and decadal changes. In the CORA3 dataset $13 \%$ of TNPD floats are flagged as 4, meaning that probably only the most severe negative drifts have been caught. The list of TNPD floats identified in the CORA3 dataset is provided, along with the CORA3 files.

Figure 12 illustrates the state of correction for APEX float profiles that are correctable in CORA3 (not TNPD and with sufficient information and surface pressure data). Among them, about $27 \%$ are not corrected and $23 \%$ have a correction equal to zero. In the latter case, this could be because the float does not need any pressure correction or, more probably, because the float has been processed in delayed mode but only for the salinity parameter. The geographical distribution of the corrections can be compared to the Fig. 5 of Barker et al. (2011). In CORA3, more profiles are corrected for a pressure drift than in the GDAC Argo dataset as of January 2009. However, a substantial amount of APEX profiles in CORA3 is still in need of pressure correction.

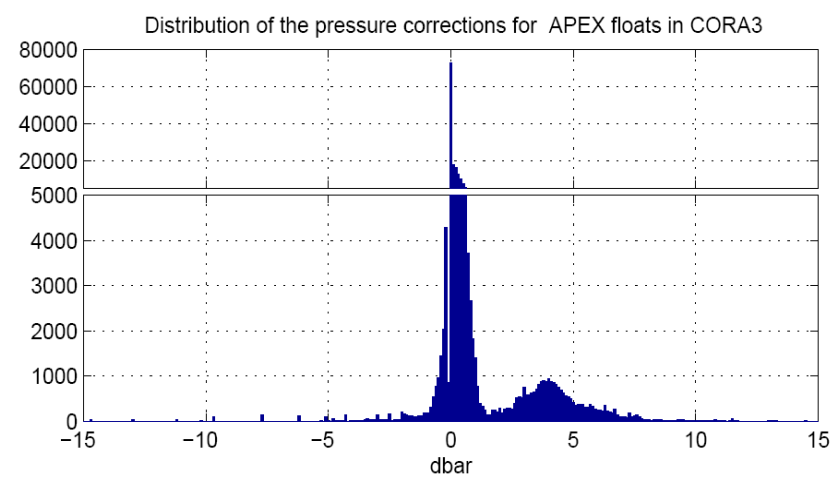

Pressure corrections for correctable APEX profiles in CORA3

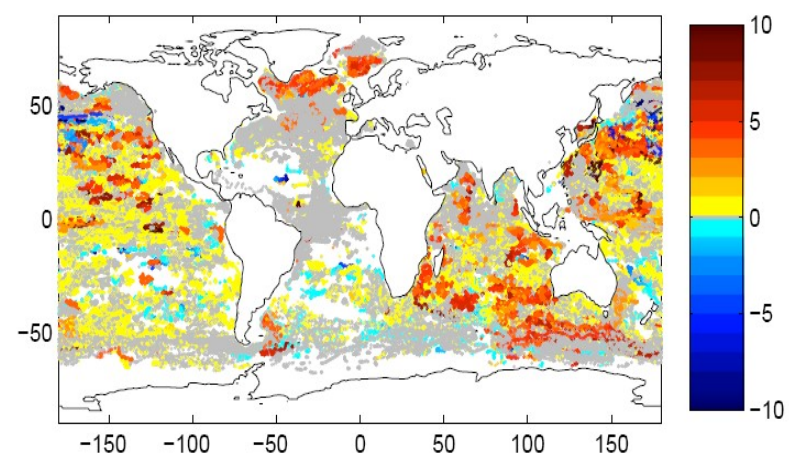

Fig. 12. (Top) Distribution of the pressure corrections for APEX float profiles that are adjusted (either in delayed mode or in real time) in CORA3 and (bottom) geographical distribution of these corrections (in dbar). Most of the corrections are for positive bias of the pressure sensor as cases of negative bias are truncated to zero for Apf-8 and earlier versions of controller. Negative bias started to be correctable with the Apf-9 version.

\subsection{Global ocean indicators}

Oceanic parameters from in-situ temperature and salinity measurements can be useful for analysing the physical state of the global ocean and have a large range of vital applications in the multidisciplinary fields of climate research studies. In particular, the estimation of GSSL is an important aspect of the analysis of climate change, as one of the most alarming consequences of anthropogenic climate change is the effect on globally averaged sea level (Bindoff et al., 2007). Recent studies have shown that about 30-50\% of global sea level rise can be explained by steric changes (Cazenave and Llovel, 2010; Church et al., 2011; Hansen et al., 2011). Thus, the rise of GSSL contributes to a large part to global sea level rise.

Several GSSL estimations based on Argo and/or other insitu observations have been derived over the past couple of years (e.g. Willis et al., 2008; Cazenave et al., 2009; Leuliette and Miller, 2009; von Schuckmann et al., 2009a, b; Cazenave and Llovel, 2010; Church et al., 2011; Hansen et al., 2011; von Schuckmann and Le Traon, 2011). However, there are substantial differences in these global statistical analyses. 


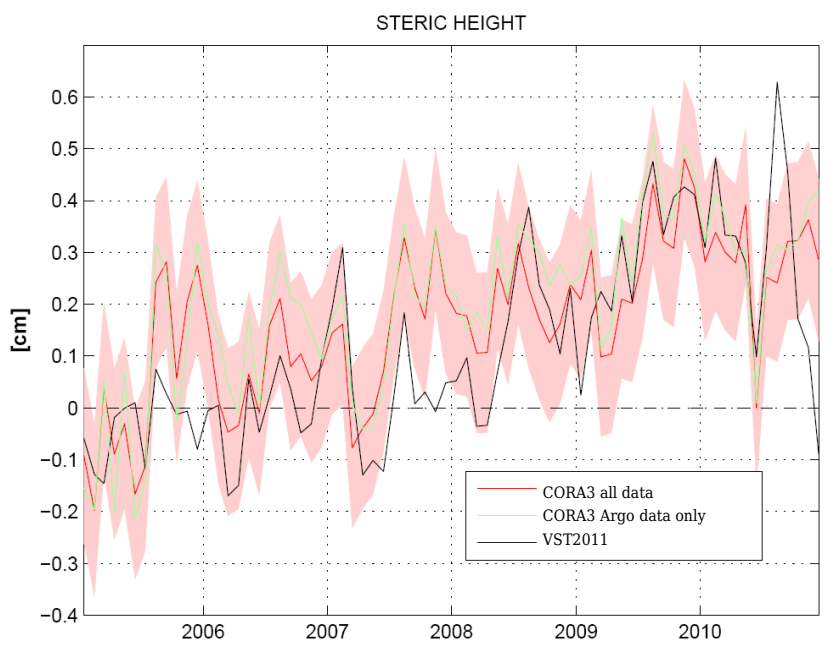

Fig. 13. Estimation of GSSL for the year 2005-2010 with a $1500 \mathrm{~m}$ reference depth. The calculation is based on a simple box averaging method described in von Scuckmann and Le Traon (2011) (VST2011). Results obtained with CORA3 (red and green curves) are compared to those obtained by VST2011. The 6-yr trends obtained are $0.64 \pm 0.12 \mathrm{~mm} \mathrm{yr}^{-1}$ with CORA3 $\left(0.58 \pm 0.10 \mathrm{~mm} \mathrm{yr}^{-1}\right.$ for CORA3 with only Argo data) and $0.69 \pm 0.14 \mathrm{~mm} \mathrm{yr}^{-1}$ for VST2011. Error bars (red areas) are shown for CORA3 (all data) and are calculated as described in VST2011. This total error includes the uncertainties on the averaged parameter in every $5^{\circ} \times 10^{\circ} \times 3$ month box and the choice of the reference climatology, but it does not take into account possible unknown systematic measurement errors.

These inconsistencies have been mainly attributed to differences in estimation periods, instrumental biases, quality control and processing issues, the role of salinity and the influence of the reference depth for GSSL calculations (Leuliette and Miller, 2009; Trenberth, 2010; Purkey and Johnson, 2010; Palmer et al., 2011; Meehl et al., 2011; Trenberth and Fasullo, 2010). In particular, GSSL from in-situ data remains a considerable challenge, as long-term trend estimations of global quantities are very sensitive to any sensor drift or systematic instrumental bias.

Von Schuckman and Le Traon (2011) have proposed a method to evaluate GSSL from irregularly distributed profiles. They divide the ocean into boxes of $5^{\circ}$ latitude, $10^{\circ}$ longitude and 3 month size. The mean for each box is then estimated using a weighted averaging method based on the analysis of Bretherton et al. (1976). In their study, von Schuckman and Le Traon only used the Argo dataset downloaded from the Coriolis data centre and rechecked it to reach the quality level required by climate change studies. In this paper we used their box averaging method to evaluate GSSL with the CORA3 dataset (using flag 1 and 2 only, i.e. good or probably good data) for the time period 2005-2010, i.e. a time period where global coverage is guaranteed mainly due to the global Argo observation array. Results obtained with the CORA3 dataset are compared to those of von Schuckmann and Le Traon (2011) in Fig. 13.

Using the CORA3 dataset, the 6-year GSSL trend is $0.64 \pm 0.12 \mathrm{~mm} \mathrm{yr}^{-1}$ (or $0.58 \pm 0.10 \mathrm{~mm} \mathrm{yr}^{-1}$ keeping only Argo data) and lies within the error bars of the von Schuckmann and Le Traon (2011) estimates. Although encouraging, there can be several explanations for this quite good agreement. One of the reasons is that the method used to compute the GSSL is robust and not very sensitive to any bad data that possibly remains in our dataset. Another reason is the possible compensatory effect in our GSSL estimate of some residual positive and negative biases. For example, Barker et al. (2011) noted that negative biases from uncorrectable (and other unusable) APEX profiles nearly compensate positive biases from correctable (but not yet corrected) APEX profiles in the global $0-700 \mathrm{~m}$ thermosteric sea level. Further careful comparisons and sensitivity studies are therefore needed to estimate GSSL with the CORA3 dataset and the users should be aware of these limitations.

\section{Conclusion and directions for future work}

This paper was intended to present the CORA3 dataset, its links with the Coriolis database (which conditions the data sources as well as real- and near-real-time quality controls) and the supplementary validation procedure applied to recheck the CORA3 dataset as a whole. This validation step relies on statistical tests designed to isolate suspicious profiles. Such profiles are then visually checked and quality flags are modified if judged necessary. No validation system is perfect, and it was necessary to deal with the number of suspicious profiles scrutinized, as this can rapidly become timeconsuming. However, human intervention was found to be required both to avoid rejecting to much good data or leaving some gross errors. When checking a large amount of profiles over the global ocean, there is the possibility that we flagged an observation as bad whereas a regional expert would have left it as good or vice-versa. Our general approach was not to flag a measurement as bad if we had some doubts, meaning that if the visual checks performed on the profile (comparison to climatology and neighbouring profiles) were not sufficient to decide if it was good or not, we left the flags unchanged. In the same way, quality flags of Argo profiles already processed in delayed mode by the PIs were generally not modified except if an error was obvious. Statistical tests could also be improved, especially in some regions (e.g. Southern Ocean) or for certain types of data (e.g. coastal moorings).

Background quality control based on the global ocean reanalysis GLORYS2V1 was implemented for this version of CORA. It proved to be a powerful tool to improve the quality of in-situ observation datasets. It also highlighted the mutual benefits that data centres and operational forecasting centres can have when working closely together: improvement of delayed time observation datasets and consequent 
improvements in ocean reanalysis quality. Such feedback from modellers will be sought in the future, particularly in the framework of the MyOceanII project.

The delivery of a global dataset such as CORA 3 should be accompanied by supporting documentation sufficient to allow different types of users to evaluate if the dataset can meet their own needs (those needs can differ if they intend to use the database, for example, in global reanalysis projects, to study a specific region or to monitor global oceanic changes). For this purpose, we developed a series of simple diagnostics to monitor data quantity and coverage and data quality. In terms of data quantity, a better coverage of the European seas will be done in partnership with the MyOceanII in-situ thematic assembly centre partners and the SeaDataNetII FP7 project. In terms of data quality, it appears to us that it is crucial to deliver sufficient information to help users evaluate the state of corrections for known instrumental biases, drifts or problems in the dataset. In this paper, we have mainly focussed on known biases or problems for Argo floats for which corrections have been made or are in progress. Future versions of CORA will include more data reprocessed in delayed mode by the originators (e.g. TAO/TRITON, PIRATA and RAMA moorings or sea mammal data).

The use of GOIs such as GSSL to evaluate the quality of a global dataset is interesting. In our case, this allows us to check the efficiency of our validation procedure compared to the one used in von Schuckmann and Le Traon (2011). However, this does not exclude the possibility that there are still unknown drifts and/or biases present in the data. Further sensitivity studies on GOI estimations need to be made in future studies to improve, and ultimately fully implement, this type of global ocean quality control in the in-situ data validation procedure.

Acknowledgements. It would have not been possible to prepare the CORA3 dataset without all those working at the Coriolis data centre who collect, decode, quality control and distribute the data, and maintain the Coriolis database. The research and operational programs that make oceanic observations are also fundamental. Argo data were collected and made freely available by the International Argo Project and the national programmes that contribute to it (http://www.argo.ucsd.edu, http://argo.jcommops.org). Argo is a pilot programme of the Global Ocean Observing System. The authors would like to thank the three anonymous reviewers whose comments greatly improved the manuscript. The authors were funded by CNRS, IFREMER, Coriolis, Mercator Ocean and the European Community Seventh Framework Program FP7/2007-2013 under grant agreement no. 218812 (MyOcean).

Edited by: M. Bell

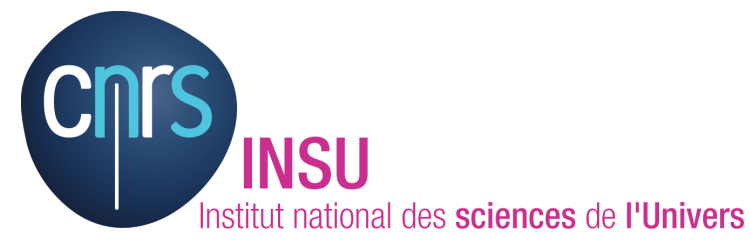

The publication of this article is financed by CNRS-INSU.

\section{References}

Antonov, J. I., Locarnini, R. A., Boyer, T. P., Mishonov, A. V., and Garcia, H. E.: World Ocean Atlas 2005, Volume 2, Salinity, edited by: Levitus, S., NOAA Atlas NESDIS 62, US Government Printing Office, Washington, DC, 182 pp., 2006.

Antonov, J. I., Seidov, D., Boyer, T. P., Locarnini, R. A., Mishonov, A. V., Garcia, H. E., Baranova, O. K., Zweng, M. M., and Johnson, D. R.: World Ocean Atlas 2009, Volume 2: Salinity, edited by: Levitus, S., NOAA Atlas NESDIS 69, US Government Printing Office, Washington, DC, 184 pp., 2010.

Barker, P. M., Dunn, J. R., Domingues, C. M., and Wijffels, S. E.: Pressure Sensor Drifts in Argo and Their Impacts, J. Atmos. Ocean. Tech., 28, 1036-1049, 2011.

Bindoff, N. L., Willebrand, J., Artale, V., Cazenave, A., Gregory, J., Gulev, S., Hanawa, K., Le Quéré, C., Levitus, S., Nojiri, Y., Shum, C. K., Talley, L. D., and Unnikrishnan, A.: Observations: Oceanic Climate Change and Sea Level, in: Climate Change 2007: The Physical Science Basis, Contribution of Working Group I to the Fourth Assessment Report of the Intergovernmental Panel on Climate Change, edited by: Solomon, S., Qin, D., Manning, M., Chen, Z., Marquis, M., Averyt, K. B., Tignor, M., and Miller, H. L., Cambridge University Press, Cambridge, United Kingdom and New York, NY, USA, 2007.

Boyer, T. P., Antonov, J. I., Baranova, O. K., Garcia, H. E., Johnson, D. R., Locarnini, R. A., Mishonov, A. V., O’Brien, T. D., Seidov, D., Smolyar, I. V., and Zweng, M. M.: World Ocean Database 2009, edited by: Levitus, S., NOAA Atlas NESDIS 66, US Gov. Printing Office, Wash., DC, 216 pp., DVDs, 2009.

Boehme, L. and Send, U.: Objective analyses of hydrographic data for referencing profiling float salinities in highly variable environments, Deep-Sea Res.-Pt. II, 52, 651-664, 2005.

Boehme, L., Lovell, P., Biuw, M., Roquet, F., Nicholson, J., Thorpe, S. E., Meredith, M. P., and Fedak, M.: Technical Note: Animalborne CTD-Satellite Relay Data Loggers for real-time oceanographic data collection, Ocean Sci., 5, 685-695, doi:10.5194/os5-685-2009, 2009.

Bretherton, F., Davis, R., and Fandry, C.: A technique for objective analysis and design of oceanic experiments applied to Mode-73, Deep-Sea Res., 23, 559-582, 1976.

Cazenave, A. and Llovel, W.: Contemporary Sea Level Rise, Annual Review of Marine Science, 2, 145-173, doi:10.1146/annurevmarine-120308-081105, 2010.

Cazenave, A., Dominh, K., Guinehut, S., Berthier, E., Llovel, W., Ramillien, G., Ablain, M., and Larnicol, G.: Sea level budget over 2003-2008: A reevaluation from GRACE space gravimetry, satellite altimetry and Argo, Global Planet. Change, 65, 83-88, 2009.

Church, J. A., White, N. J., Konikow, L. F., Domingues, C. M., Cogley, J. G., Rignot, E., Gregory, J. M., van den Broeke, M. 
R., Monaghan, A. J., and Velicogna, I.: Revisiting the Earth's sea level and energy budgets from 1961 to 2008, Geophys. Res. Lett., 38, L18601, doi:10.1029/2011GL048794, 2011.

Coatanoan, C. and Petit de la Villéon, L.: Coriolis Data Centre, In-situ data quality control procedures, Ifremer report, $17 \mathrm{pp}$., available at: http://www.coriolis.eu.org/content/download/4918/ 36060/file/cordo-rap-04-047-quality-control.pdf (last access: February 2012), 2005.

Conlee, D. T. and Moersdorf, P. F.: The NWS Marine Observation Network: Coastal Marine Component of Multiple Observing Systems, Ninth Symposium on Integrated Observing and Assimilation Systems for the Atmosphere, Oceans, and Land Surface (IOAS-AOLS), American Meteorological Society, 2005.

Curry, R.: HydroBase 2 - A Database of Hydrographic Profiles and Tools for Climatological Analysis. Technical Reference, Preliminary Draft, November 2001. Woods Hole Oceanographic Institution, Woods Hole, Massachusetts, 81 pp., 2001.

di Nezio, P. N. and Goni, G.: Direct Evidence of Changes in the XBT Fall-rate Bias During 1986-2008, J. Atmos. Ocean. Tech., 28, 1569-1578, doi:10.1175/JTECH-D-11-00017.1, 2011.

Edwards, M. H. and Arvidson, R. E.: Report MGG-2, Relief of the surface of the Earth, edited by: Heirtzler, J. R., published for World Data Center A for Marine Geology and Geophysics by the National Geophysical Data Center, Boulder, CO, 1985.

Ferry, N., Parent, L., Garric, G., Barnier, B., Jourdain, N. C., and the Mercator Ocean team: Mercator global eddy permitting ocean reanalysis GLORYS1V1: Description and results, Mercator Quarterly Newsletter 36, available at: http://www.mercatorocean.fr/fre/actualites-agenda/newsletter/newsletter-Newsletter -36-Data-assimilation-and-its-application-to-Ocean-Reanalyses, (last access: January 2013), January 2010.

Ferry, N., Barnier, B., Guinehut, S., Haines, K., Masina, S., Parent, L., Mulet, S., Valdivieso, M., and Storto, A.: The global ocean reanalysis effort of MyOcean: description and early results, EGU Poster, Geophys. Res. Abstr., EGU2011-11250, EGU General Assembly 2011, Vienna, Austria, 2011.

Gaillard, F., Autret, E., Thierry, V., Galaup, P., Coatanoan, C., and Loubrieu, T.: Quality controls of large Argo datasets, J. Atmos. Ocean. Tech., 26, 337-351, 2009.

Gouretski, V. and Koltermann, K.: How much is the ocean really warming?, Geophys. Res. Lett., 34, L01610, doi:10.1029/2006GL027834, 2007.

Gouretski, V. and Reseghetti, F.: On depth and temperature biases in bathythermograph data: Development of a new correction scheme based on analysis of a global ocean database, Deep-Sea Res.-Pt. I, 57, 812-833, 2010.

Guinehut, S., Coatanoan, C., Dhomps, A.-L., Le Traon, P.-Y., and Larnicol, G.: On the Use of Satellite Altimeter Data in Argo Quality Control, J. Atmos. Ocean. Tech., 26, 395-402, 2009.

Guinehut, S., Dhomps, A.-L., Larnicol, G., and Le Traon, P.Y.: High resolution 3-D temperature and salinity fields derived from in situ and satellite observations, Ocean Sci., 8, 845-857, doi:10.5194/os-8-845-2012, 2012.

Gronell, A. and Wijffels, S. E.: A Semiautomaed Approach for Quality Controlling Large Historical Ocean Temperature Archives, J. Atmos. Ocean. Tech., 25, 990-1003, doi:10.1175/JTECHO539.1, 2008.

Hamon, M., Reverdin, G. and Le Traon, P.-Y.: Empirical correction of XBT data, J. Atmos. Ocean. Tech., 29, 960-973,
doi:10.1175/JTECH-D-11-00129.1, 2012.

Hanawa, K., Rual, P., Bailey, R., Si, A., and Szabados, M.: A new depth-time equation for Sippican or TSK T-7, T-6 and T-4 expendable bathythermographs (XBT), Deep-Sea Res.-Pt. I, 42, 1423-1451, 1995.

Hansen, J., Sato, M., Kharecha, P., and von Schuckmann, K.: Earth's energy imbalance and implications, Atmos. Chem. Phys., 11, 13421-13449, doi:10.5194/acp-11-13421-2011, 2011.

Ingleby, B. and Huddleston, M.: Quality control of ocean temperature and salinity profiles - historical and real-time data, J. Marine Syst., 65, 158-175, doi:10.1016/j.jmarsys.2005.11.019, 2007.

Ishii, M. and Kimoto, M.: Reevaluation of historical ocean heat content variations with time-varying XBT and MBT depth bias corrections, J. Oceanogr., 65, 287-299, doi:10.1007/s10872-0090027-7, 2009.

Johnson, D. R., Boyer, T. P., Garcia, H. E., Locarnini, R. A., Baranova, O. K. and Zweng, M. M.: World Ocean Database 2009 Documentation. Edited by Sydney Levitus. NODC Internal Report 20, NOAA Printing Office, Silver Spring, MD, 175 pp., 2009.

Johnson, G. C.: Revised XCTD fall-rate equation coefficients from CTD data, J. Atmos. Ocean. Tech., 12, 1367-1373, 1995.

Kizu, S., Sukigara, C., and Hanawa, K.: Comparison of the fall rate and structure of recent T-7 XBT manufactured by Sippican and TSK, Ocean Sci., 7, 231-244, doi:10.5194/os-7-231-2011, 2011.

Lellouche, J.-M., Le Galloudec, O., Drévillon, M., Régnier, C., Greiner, E., Garric, G., Ferry, N., Desportes, C., Testut, C.-E., Bricaud, C., Bourdallé-Badie, R., Tranchant, B., Benkiran, M., Drillet, Y., Daudin, A., and De Nicola, C.: Evaluation of real time and future global monitoring and forecasting systems at Mercator Océan, Ocean Sci. Discuss., 9, 1123-1185, doi:10.5194/osd9-1123-2012, 2012.

Leuliette, E. W. and Miller, L.: Closing the sea level rise budget with altimetry, Argo, and GRACE, Geophys. Res. Lett., 36, L04608, doi:10.1029/2008GL036010, 2009.

Levitus, S.: Climatological Atlas of the World Ocean, NOAA Professional Paper 13, US Government Printing Office, Rockville, MD, 190 pp., 1982.

Levitus, S., Antonov, J., Boyer, T., Locamini, R. A., Garcia, H. E., and Mishonov, A. V.: Global ocean heat content 1955-2008 in light of recently revealed instrumentation problems, Geophys. Res. Lett., 36, L07608, doi:10.1029/2008GL037155, 2009.

Locarnini, R. A., Mishonov, A. V., Antonov, J. I., Boyer, T. P., and Garcia, H. E.: World Ocean Atlas 2005, Volume 1: Temperature, edited by: Levitus, S., NOAA Atlas NESDIS 61, US Government Printing Office, Washington, DC, 182 pp., 2006

Locarnini, R. A., Mishonov, A. V., Antonov, J. I., Boyer, T. P., Garcia, H. E., Baranova, O. K., Zweng, M. M. and Johnson, D. R.: World Ocean Atlas 2009, Vol. 1, Temperature, edited by: Levitus, S., NOAA Atlas NESDIS 68, US Government Printing Office, Washington, DC, 184 pp., 2010.

Lozier, M. S., Owens, W. B., and Curry, R. G.: The climatology of the North Atlantic, Prog. Oceanogr., 36, 1-44, 1995.

Lyman, J. M., Good, S. A., Gouretski, V. V., Ishii, M., Johnson, G. C., Palmer, M. D., Smith, D. M., and Willis, J. K.: Robust warming of the global upper ocean, Nature, 465, 334-337, doi:10.1038/nature09043, 2010.

Meehl, G. A., Arblaster, J. M., Fasullo, J. T., Hu, A., and Trenberth, K. E.: Model-based evidence of deep-ocean heat uptake during 
surface-temperature hiatus periods, Nature Climate Change, 1, 360-364, doi:10.1038/NCLIMATE1229, 2011.

Owens, W. B. and Wong, A. P. S.: An improved calibration method for the drift of the conductivity sensor on autonomous CTD profiling floats by $\Theta-S$ climatology, Deep-Sea Res.-Pt. I, 56, 450457, 2009.

Palmer, M. D., McNeall, D. J., and Dunstone, N. J.: Importance of the deep ocean for estimating decadal changes in Earth's radiation balance, Geophys. Res. Lett., 38, L13707, doi:10.1029/2011GL047835, 2011.

Purkey, S. G. and Johnson, G. C.: Warming of global abyssal and deep Southern Ocean between the 1990s and 2000s: contributions to global heat and sea level rise budgets, J. Climate, 23, 6336-6351, 2010.

Roemmich, D., Johnson, G. C., Riser, S., Davis, R., Gilson, J., Owens, W. B., Garzoli, S. L., Schmid, C., and Ignaszewski, M.: The Argo Program: Observing the global ocean with profiling floats, Oceanography, 22, 34-43, doi:10.5670/oceanog.2009.36, 2009.

Seaver, G. A. and Kuleshov, S.: Experimental and Analytical Error of the Expendable Bathythermograph, J. Phys. Oceanogr., 12, 592-600, 1982.

Souza, J. M. A. C., de Boyer Montégut, C., Cabanes, C., and Klein, P.: Estimation of the Agulhas ring impacts on meridional heat fluxes and transport using ARGO floats and satellite data, Geophys. Res. Lett., 38, L21602, doi:10.1029/2011GL049359, 2011.

Thadathil, P., Saran, A. K., Gopalakrishna, V. V., Vethamony, P., Araligidad, N., and Bailey, R.: XBT Fall Rate in Waters of Extreme Temperature: A Case Study in the Antarctic Ocean, J. Atmos. Ocean. Tech., 19, 391-396, 2002.

Trenberth, K.: The ocean is warming, isn't it?, Nature, 465, 304304, 2010

Trenberth, K. E. and Fasullo, J. T.: Tracking Earth's energy, Science, 328, 316-317, 2010. von Schuckmann, K. and Le Traon, P.-Y.: How well can we derive Global Ocean Indicators from Argo data?, Ocean Sci., 7, 783791, doi:10.5194/os-7-783-2011, 2011.

von Schuckmann, K., Gaillard, F., and Le Traon, P.-Y.: Estimating Global Ocean indicators from a gridded hydrographic field during 2003-2008, available at: Mercator Quarterly Newsletter 33, 3-10, http://www.mercator-ocean.fr/eng/actualitesagenda/newsletter/newsletter-Newsletter-33-Ocean-indices-forOcean-climate-monitoring, 2009a.

von Schuckmann, K., Gaillard, F., and Le Traon, P.-Y.: Global hydrographic variability patterns during 2003-2008, J. Geophys. Res., 114, C09007, doi:10.1029/2008JC005237, 2009b.

Wijffels, S. E., Willis, J., Domingues, C. M., Barker, P., White, N. J., Gronell, A., Ridgway, K., and Church, J. A.: Changing Expendable Bathythermograph Fall Rates and Their Impact on Estimates of Thermosteric Sea Level Rise, J. Climate, 21, 56575672, doi:10.1175/2008JCLI2290.1, 2008.

Willis, J. K., Lyman, J. M., Johnson, G. C., and Gilson, J.: Correction to "Recent cooling of the upper ocean", Geophys. Res. Lett., 34, L16601, doi:10.1029/2007GL030323, 2007.

Willis, J. K., Chambers, D. P., and Nerem, R. S.: Assessing the globally averaged sea level budget on seasonal to interannual timescales, J. Geophys. Res., 113, C06015, doi:10.1029/2007JC004517, 2008.

Wong, A. L. S., Johnson, J. M., and Owens, W. B.: Delayed-Mode Calibration of Autonomous CTD Profiling Float Salinity Data by $\Theta-S$ Climatology, J. Atmos. Ocean.-Tech., 20, 308-318, 2003.

Wong, A. L. S, Keeley, R., Carval, T., and the Argo Data Management Team: Argo quality control manual, Version 2.7, $47 \mathrm{pp}$. available at: http://www.argodatamgt.org/content/download/341/ 2650/file/argo-quality-control-manual-V2.7.pdf (last access: February 2012), 2012. 